\title{
8. PRELIMINARY ANALYSIS OF OCEAN-BOTTOM AND SUB-BOTTOM MICROSEISMIC NOISE DURING THE NGENDEI EXPERIMENT ${ }^{1}$
}

\author{
Richard G. Adair, John A. Orcutt, and Thomas H. Jordan, Scripps Institution of Oceanography²
}

\begin{abstract}
Simultaneous measurements of ambient microseismic noise at and below the seafloor are compared over the band $0.2-7.0 \mathrm{~Hz}$ using data collected during the Ngendei Seismic Experiment. Borehole data were collected with a triaxial set of seismometers which rested unclamped at the bottom of DSDP Hole 595B, $124 \mathrm{~m}$ sub-bottom, $54 \mathrm{~m}$ within basement rock. Ocean-bottom data were collected with six 4-component ocean-bottom seismographs (OBSs) deployed at distances ranging from 0.5 to $30 \mathrm{~km}$ from the borehole. Noise spectra of displacement power density at both borehole and ocean-bottom sites typically displayed the microseism peak between 0.15 and $0.25 \mathrm{~Hz}$. Vertical-component spectra fell off from this peak at $60-80 \mathrm{~dB} /$ decade with various peaks superposed. The peaks suggest that the noise consisted of seismic waves trapped in the seafloor. Vertical ocean-bottom and borehole noise levels are nearly identical at the microseism peak, on the order of $10^{8} \mathrm{~nm}^{2} / \mathrm{Hz}$, but OBS values exceed Marine Seismic System (MSS) values by $10 \mathrm{~dB}$ or more at frequencies between 0.5 and $7 \mathrm{~Hz}$. In the borehole, horizontal noise levels were essentially the same as the vertical-component levels. At the ocean bottom, horizontal noise levels exceed vertical levels between $0.4 \mathrm{and} 7 \mathrm{~Hz}$, but have comparable values at the microseism peak. Ocean-bottom pressure measurements of ambient noise are comparable to other published measurements; Ngendei values are on the order of $10^{4} \mathrm{~Pa}^{2} / \mathrm{Hz}$ at the microseism peak. Leg 91 noise measurements contrast with those from the prototype MSS deployment during DSDP Leg 78B, when levels at a proximate seafloor site exceeded borehole levels by $10-30 \mathrm{~dB}$ over the entire band of valid comparisons $(0.16-2.2 \mathrm{~Hz})$. Between 0.3 and $2.2 \mathrm{~Hz}$, Leg 78B borehole levels were greater than those of Leg 91 by 10-20 dB. Leg 78B spectra did not display any obvious peaks other than the microseism peak, where high vertical-component coherence was observed between pairs of OBSs separated by $0.7 \mathrm{~km}$. At the quietest land sites, vertical-component noise levels at the microseism peak are 10-30 dB lower than those measured in the borehole during Leg 91. At higher frequencies, the noise levels measured in the borehole still exceed those of the quietest land sites, but are lower than at average land sites.
\end{abstract}

\section{INTRODUCTION}

Poor sensitivity and high levels of instrumental noise plagued the earliest generation of ocean-bottom seismographs (OBSs) employed during the 1960s. Most of these efforts were funded by the Advanced Research Projects Agency (ARPA) of the Air Force through Project VELA Uniform to facilitate the seismic discrimination of nuclear explosions (Prentiss and Ewing, 1963; Bradner and Dodds, 1964; Latham and Sutton, 1966; Latham and Nowroozi, 1968; Schneider and Backus, 1964; and Schneider et al., 1964). It was hoped that ambient oceanbottom noise levels would be substantially lower than at land sites, but in fact they were found to be comparable or higher. This result, coupled with the logistical difficulty of employing OBSs, led to the eventual abandonment of this research effort. The current revitalization of OBS usage is due primarily to recent developments in semiconductor technology and hardware, particularly in digital recording techniques, and they have been used primarily to investigate seafloor structure through refraction experiments. Several problems still arise, however, from the nearly ubiquitous blanket of sediments at the ocean bottom. OBSs must contend with poor coupling

\footnotetext{
${ }^{1}$ Menard, H. W., Natland, J., Jordan, T. H., Orcutt, J. A., et al., Init. Repts. DSDP, 91: Washington (U.S. Govt. Printing Office).

2 Addresses: (Adair, Orcutt) Institute of Geophysics and Planetary Physics (A-025), Scripps Institution of Oceanography, La Jolla, CA 92093, (Adair, present address: Rockwell Hanford Operations, Energy Systems Group, P.O. Box 800, Richland, WA 99352); (Jordan, present address) Department of Earth, Atmospheric, and Planetary Sciences, Massachusetts Institute of Technology, Cambridge, MA 02139.
}

and signal "ringing" caused by unconsolidated sediments (Sutton et al., 1981), as well as with the inherent difficulty of observing important converted shear phases (Spudich and Orcutt, 1980). A final difficulty, which is the primary interest of this chapter, is the high ambient noise levels at the ocean bottom, thought to be due to noise propagation as low-order trapped modes confined near the interface between the seafloor and the ocean bottom. The high noise levels may be mitigated by emplacing seismometers in the more rigid material underlying the sediments. Accordingly, interest has been kindled in the use of marine borehole seismographs as an alternative to OBSs.

Several Deep Sea Drilling Project (DSDP) legs have been devoted to "oblique refraction" studies employing commercially available seismometer systems in boreholes (Stephen et al., 1980, 1983). Because of high instrumental noise levels, these data are not suitable for ambient noise analysis. Two marine borehole systems have recently been developed to answer these needs: the ocean subbottom seismometer (OSS) of the Hawaii Institute of Geophysics and the Marine Seismic System (MSS) funded by the Defense Advanced Research Projects Agency (DARPA). A detailed description of the OSS and its operational use is given in the Leg 88 part of this volume and in Duennebier and Blackinton (1983).

The feasibility of the MSS design and installation procedure were successfully tested with the deployment of a prototype borehole instrumentation package in Hole 395A during DSDP Leg 78B in late March 1981 (Hyndman, Salisbury et al., 1984). Noise data and refraction signals 
were recorded on the prototype's two vertical-component seismometers over a 26 -hr. operational period. Simultaneous measurements of vertical-component noise at a nearby seafloor site were higher than the borehole levels by at least $10 \mathrm{~dB}$ between 0.16 and $2.2 \mathrm{~Hz}$ (Adair et al., 1984). Encouraged by the Leg 78B results, researchers attempted to deploy the complete MSS ensemble on DSDP Leg 88 , but were thwarted by foul weather and drilling problems (Duennebier et al., Leg 88 part of this volume). The MSS deployment was rescheduled for Leg 91, originally a DSDP transit leg between Wellington, New Zealand, and Papeete, Tahiti.

The Ngendei Experiment, which includes DSDP Leg 91, was designed to answer several outstanding questions regarding the generation and propagation of microseismic noise and the relative characteristics of seismic signals at and below the seafloor. In addition to the MSS, the experiment employed an array of six OBSs at various distances from the drill site. This chapter presents a preliminary analysis of the Leg 91 seismic data regarding the relative character and levels of microseismic noise at and below the seafloor.

\section{MARINE SEISMIC SYSTEM DESCRIPTION}

\section{Marine Seismic System}

Only the salient features of the MSS operations and seismic instrumentation will be considered here. Detailed descriptions of the MSS and its operational use are found elsewhere in this volume (Harris et al.; Adair, Harris, et al., this volume).

When fully operational, the MSS comprises a borehole sensor package connected by coaxial cable to an untended ocean-bottom recording system. The borehole package and a companion shipboard recording console, referred to here as the Teledyne system, were developed by Teledyne-Geotech. The ocean-bottom recording system and its shipboard counterpart, referred to as Gould systems, were developed by Gould, Inc. Global Marine Development Corporation built a carriage for transporting the borehole package to the seafloor at the bottom end of the drillstring. The Naval Civil Engineering Laboratory in Port Hueneme, CA, designed and tested a submerged mooring which facilitates the installation and recovery of the ocean-bottom recording system.

The MSS data used in this paper are transcriptions of the original data obtained from DARPA's Center for Seismic Studies in Alexandria, Virginia.

\section{MSS Instrumentation}

The instrumentation is housed in a $600.6-\mathrm{cm}$-long pressure vessel of outside diameter $20.3 \mathrm{~cm}$. The instrumentation includes seismic sensors, accelerometers, and internal pressure and temperature monitors. Above the pressure vessel is a $343.9-\mathrm{cm}$-long cable terminator unit, and below it a $43.8-\mathrm{cm}$-long impact tip. The cable terminator incorporates cable-isolating and holelock mechanisms.

The MSS sensors are four Teledyne model S-750 seismometers configured as a triaxial set (two orthogonal horizontals and one vertical) and a redundant backup vertical component. The backup sensor is located 175.5 $\mathrm{cm}$ below the primary vertical sensor. Output from the three primary sensors is filtered in midperiod $(0.05-10 \mathrm{~s})$ and short-period (0.05-2 s) bands whereas output from the backup sensor is passed through the short-period band only. The resultant seven data streams are then digitized and transmitted to the recording devices via coaxial cable. For convenience, the sensors and data channels are labeled in subsequent discussion. The horizontal sensors are $\mathrm{X}$ and $\mathrm{Y}$, and the primary and backup verticals are $\mathrm{Z}$ and $\mathrm{B}$, respectively. The prefixes " $\mathrm{S}$ " and " $\mathrm{M}$ " will refer to the passband of a particular channel.

\section{MSS Recording Systems}

The MSS data are collected either on two shipboard systems employed for diagnostic checkout and recording redundancy or on an ocean-bottom recording unit. The Gould systems differ vastly from the Teledyne system in digitizing scheme and postdigitizing processing method. Briefly, the Teledyne system samples the data after lowpassing them, whereas the Gould systems convolve the data with a digital low-pass filter after sampling them. The Gould data are initially sampled at an extremely high rate to insure that the fall-off of the instrument response prevents high-frequency aliasing, and are then resampled at the desired rate.

\section{Teledyne Shipboard Recorder}

Data destined for the shipboard Teledyne system are sampled, amplified at one of four gains $(\times 1, \times 8, \times 32$, and $\times 128)$, and represented as 14-bit integers augmented by a 2-bit gain code. Each datum is separately amplified, thereby achieving a 21-bit dynamic range with 14bit resolution. Midperiod data are routinely digitized at $4 \mathrm{sample} / \mathrm{s}$, and the short-period data at $40 \mathrm{sample} / \mathrm{s}$, although either of the short-period vertical channels may be sampled at $80 \mathrm{sample/s}$ by excluding the other.

\section{Gould Shipboard and Ocean-Bottom Recorders}

Data transmitted to the ocean-bottom recorder and its shipboard counterpart are represented with a delta modulator encoding technique. The encoded streams are transmitted to the recording unit where they are digitally convolved with a low-pass, zero phase-shift filter. The filter amplitude response is nearly flat below $75 \%$ of the ultimate Nyquist frequency, and thereafter falls at approximately $750 \mathrm{~dB} /$ decade. The low-passed digital data are then resampled at their proper rates and buffered to tape with timing and system status information. Midperiod data are recorded at a rate of $4 \mathrm{sample} / \mathrm{s}$, and the short-period data at $40 \mathrm{sample} / \mathrm{s}$. Details of the sampling technique and the low-pass filter are given elsewhere in this volume. The resultant digital data in principle have 24-bits of both dynamic range and resolution.

The Gould ocean-bottom recording system employs 20 tape drives to achieve a 45 -day maximum operating period. Power is provided by two battery packs. Each of the packs and the data-processing electronics is housed in separate aluminum spheres. The three spheres and various hydroacoustic instruments are mounted on an aluminum framework. A sediment-penetrating flange rim- 
ming the framework bottom secures the recorder package on the seafloor. The flange is bound by magnesiumalloy bolts, which corrode, allowing detachment of the superstructure and aiding recovery of the recorder.

\section{MSS Instrument Responses}

Figure 1A shows the instrument responses of the MSS systems. The dashed lines at high frequencies depict the effect of the Gould low-pass filter. In the absence of this low-pass filter, the mid-period response is peaked at approximately $1.2 \mathrm{~Hz}$ and falls off at 40 and $150 \mathrm{~dB} / \mathrm{dec}-$ ade towards lower and higher frequencies, respectively. The short-period response is peaked at approximately 15 $\mathrm{Hz}$ and declines gently toward lower and higher frequencies at 40 and $45 \mathrm{~dB} /$ decade, respectively. The Gould low-pass filter falls at approximately $750 \mathrm{~dB} /$ decade beyond $75 \%$ of the Nyquist frequencies.

\section{OCEAN-BOTTOM SEISMOGRAPH DESCRIPTION}

The six OBSs are modifications of the four-component, digital event-recorders described by Moore et al. (1981). The most important modifications incorporated by the Ngendei OBSs are an increased memory capacity and a seismograph response which emphasizes frequencies below $1 \mathrm{~Hz}$. Both of these changes were necessitated by the needs of earthquake recording. Orcutt et al. (this volume) provide a complete description of the OBS instrumentation employed on the Ngendei Experiment; we summarize it here.

The OBS sensors are a $1-\mathrm{Hz}$ triaxial set of velocitytransducer seismometers, the Mark Products Inc. model L-4-3D, and an omnidirectional piezoelectric hydrophone, the Ocean and Atmospheric Sciences Inc. model E-2PD. The seismometers are configured as two orthogonal hori- zontals and a vertical. For convenience in later discussion, the vertical, two horizontal, and hydrophone channels will be labeled $\mathrm{Z}, \mathrm{X}, \mathrm{Y}$ and $\mathrm{H}$, corresponding to OBS data channels 1 through 4 , respectively.

A gimbaled mounting corrects, to within $1^{\circ}$, seismometer tilts of up to $15^{\circ}$ from the vertical. The orientations of the horizontal components are not directly determined and must be inferred from, for example, particle motion studies of seismic refraction shots. The seismic sensors and electronics are housed in a buoyant aluminum sphere mounted on a disposable tripod. A collar of syntactic foam enhances overall buoyancy. Acoustic communication with the OBS tending ship makes it easier to locate the capsule and monitor its state of health. Explosive bolts, detonated either by acoustic command or by schedule, free the sphere to float to the surface for recovery.

Sensor outputs are amplified, bandpassed, sampled 128 times per second with a 12-bit word, and continuously stored with gain and timing information in a cyclically overwritten buffer. Buffer lengths of approximately 13 and $58 \mathrm{~s}$ were used during the Ngendei Experiment. The data are buffered to avoid the mechanical shaking and electrical transients caused by recorder operation. Recording proceeds either when a triggering criterion is met or at scheduled times.

Trigger status and channel gains are determined from averages of the digital data. Event triggers are established with a comparison criterion of short-term and long-term averages of vertical-component data. A channel's gain is updated at regular intervals and changed only then if the long-term average of that channel's output falls outside preset bounds of a few least-significant bits. The gain is constrained to be a power of two between 1 and 512, and to change only in a single, 6-dB
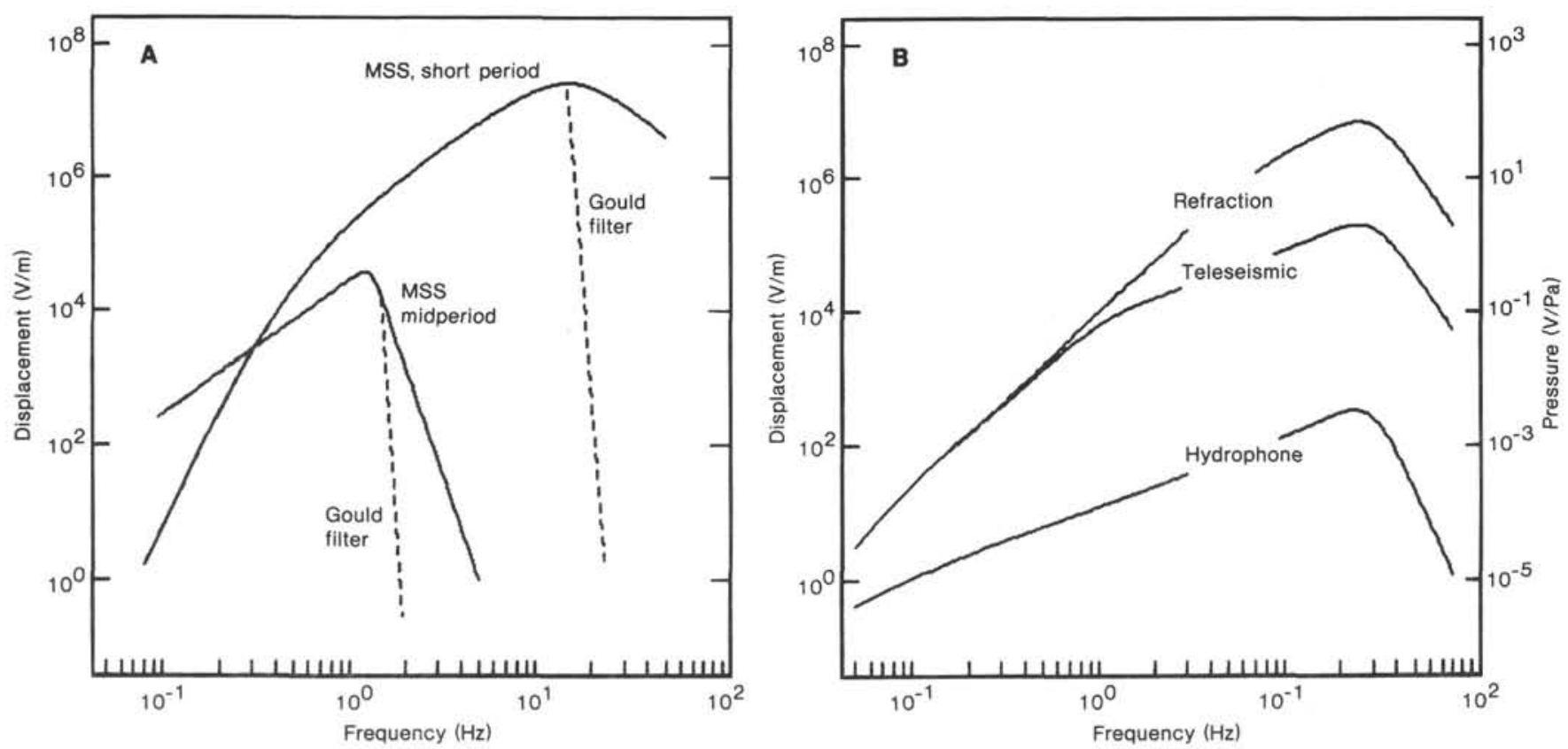

Figure 1. Displacement responses of (A) Marine Seismic System (MSS) and (B) ocean-bottom seismograph (OBS) instrumentation used during the Ngendei Experiment. A. The Gould MSS midperiod and short-period responses differ from the Teledyne responses by the low-pass digital filter, shown with dashed lines. B. OBS seismometer and hydrophone responses. Two responses were available for the OBSs. 
step (a factor of two in amplitude). Because this gainranging scheme operates over time scales on the order of minutes, the gain is essentially fixed during an event, so that the dynamic range is only 12 bits, with 12 -bit resolution.

Bandpass filters for the data streams include a response-shaping stage which reduces the dynamic range occupied by ambient noise. Acoustic and seismic noise, which fall sharply with frequency from a peak near 0.2 $\mathrm{Hz}$, may be compensated for with responses emphasizing high frequencies over low. On the other hand, the triggering algorithm is more sensitive to teleseisms if lower frequencies are emphasized, because teleseisms are typically depleted in high frequencies. To meet these varied needs, two responses for the seismic channels, shown in Figure 1B, were employed. The hydrophone response was not altered for teleseismic deployments.

\section{OPERATIONS}

Figure 2 charts a select chronology of operations and events. The events of the Ngendei Experiment are conveniently segregated into three phases according to whether or not the Gould ocean-bottom recorder was in use. These three phases also roughly demark periods during which the tending ships Glomar Challenger and Melville were or were not present. Challenger was responsible for installation of the MSS sensors and seafloor recorder, and Melville conducted MSS support operations, site surveys, and instrumentation recovery as well as all OBS operations. The presence of the ship is of concern because microseismic noise measurements are severely contaminated by ship-generated noise in the frequency band discussed here. Ships were absent only during the second phase.
The 20-day-long first phase included site selections, borehole drilling, instrumentation deployment, and a refraction experiment. The second phase comprised a 40 day period of untended earthquake and noise recording. The instrumentation was recovered during the final phase.

Figures 3 and 4 show the MSS borehole site and the OBS locations throughout the Ngendei Experiment. The MSS site is computed relative to the best satellite estimates of Challenger's positions. Octagons centered on ellipses depict computed OBS locations (octagons) and their $95 \%$ confidence bounds (ellipses) based on leastsquares modeling of satellite and acoustic ranging data (Creager and Dorman, 1982). Diamonds denote OBS drop points estimated from either satellite navigation or Melville radar ranging of Challenger. Capsules are referred to by the first two letters of their names and a numeral denoting the deployment number. Tables 1 and 2 list the particulars of each OBS, including range and azimuth from the borehole site, response type and preevent buffer length.

During the first phase, four of the six OBSs were placed in pairs $0.6-0.7 \mathrm{~km}$ to the north and southwest of the borehole (Figure 3A) for refraction signal recording, and the other two $25-30 \mathrm{~km}$ to the east-northeast (Figure 3B) for triggered earthquake recording. All OBSs recorded noise at various regular intervals. Five distinct refraction lines were shot.

The second phase began with the redeployment of the OBSs in a triangular array and installation of the MSS ocean-bottom recorder and its recovery mooring. Two of the OBSs formed $25-\mathrm{km}$ legs at approximate right angles to the south and east of the MSS site (Figure 4A). The four other capsules were clustered within $3 \mathrm{~km}$ to the west and north of the MSS borehole (Figure 4B).

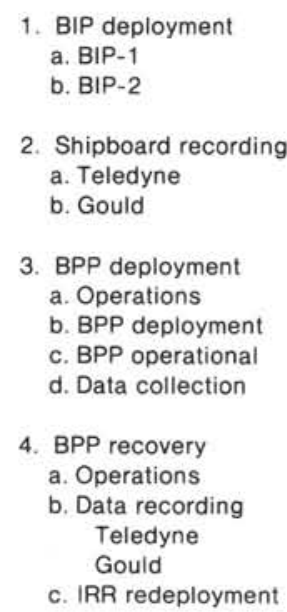

1. BIP deployment a. BIP-1

b. BIP-2

2. Shipboard recording a. Teledyne b. Gould

3. BPP deployment a. Operations b. BPP deployment c. BPP operational d. Data collection

4. BPP recovery a. Operations

b. Data recording Teledyne Gould c. IRR redeployment

5. Refraction lines

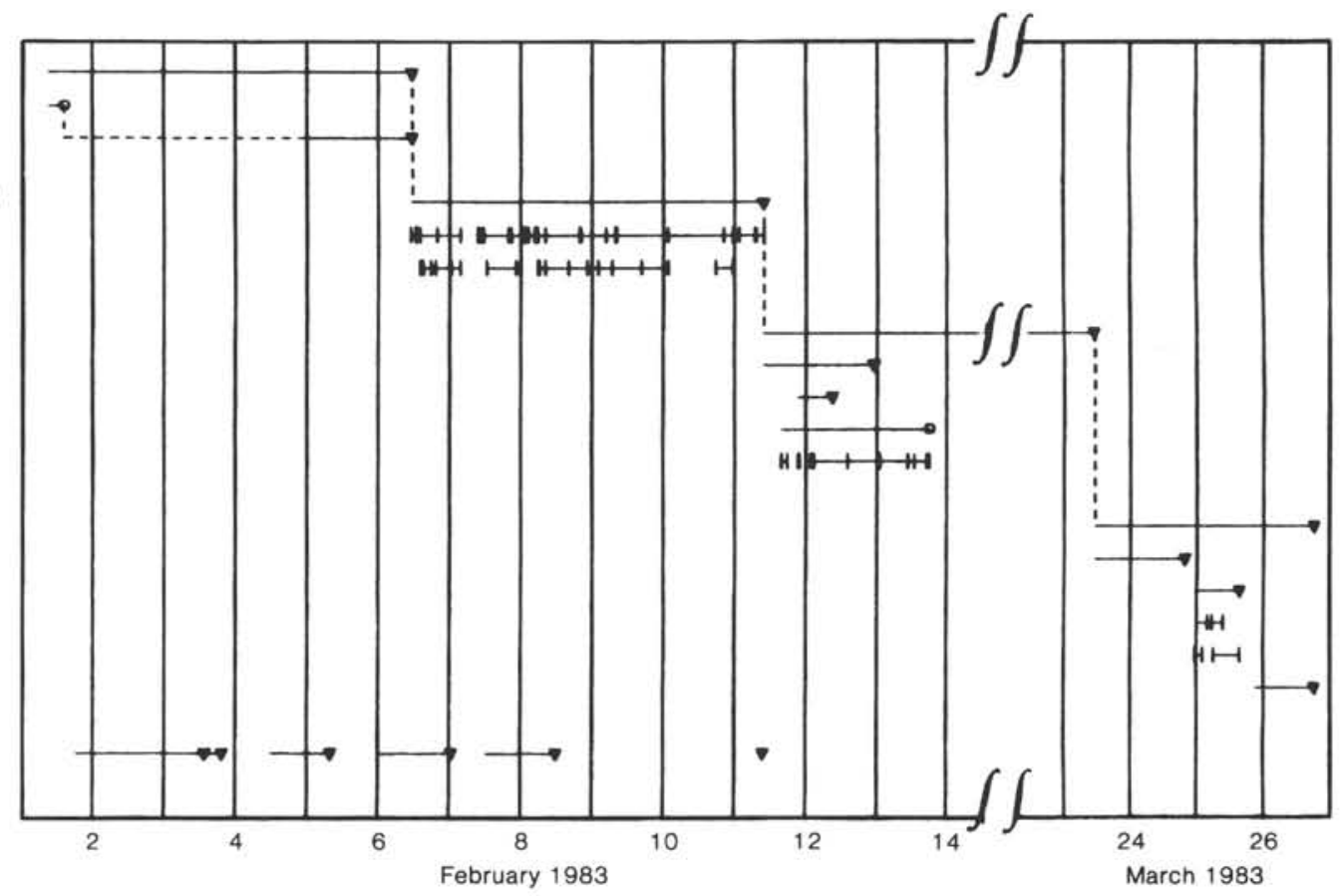

Figure 2. Chronology of events during the Ngendei Experiment pertinent to the noise study. Coordinated Universal Time (CUT) data are given along the bottom axis, with a break between mid-February 1983 and late March 1983, when the teleseismic experiment took place and noise samples were recorded by each OBS at 24 -hr. intervals. See text for explanation. 

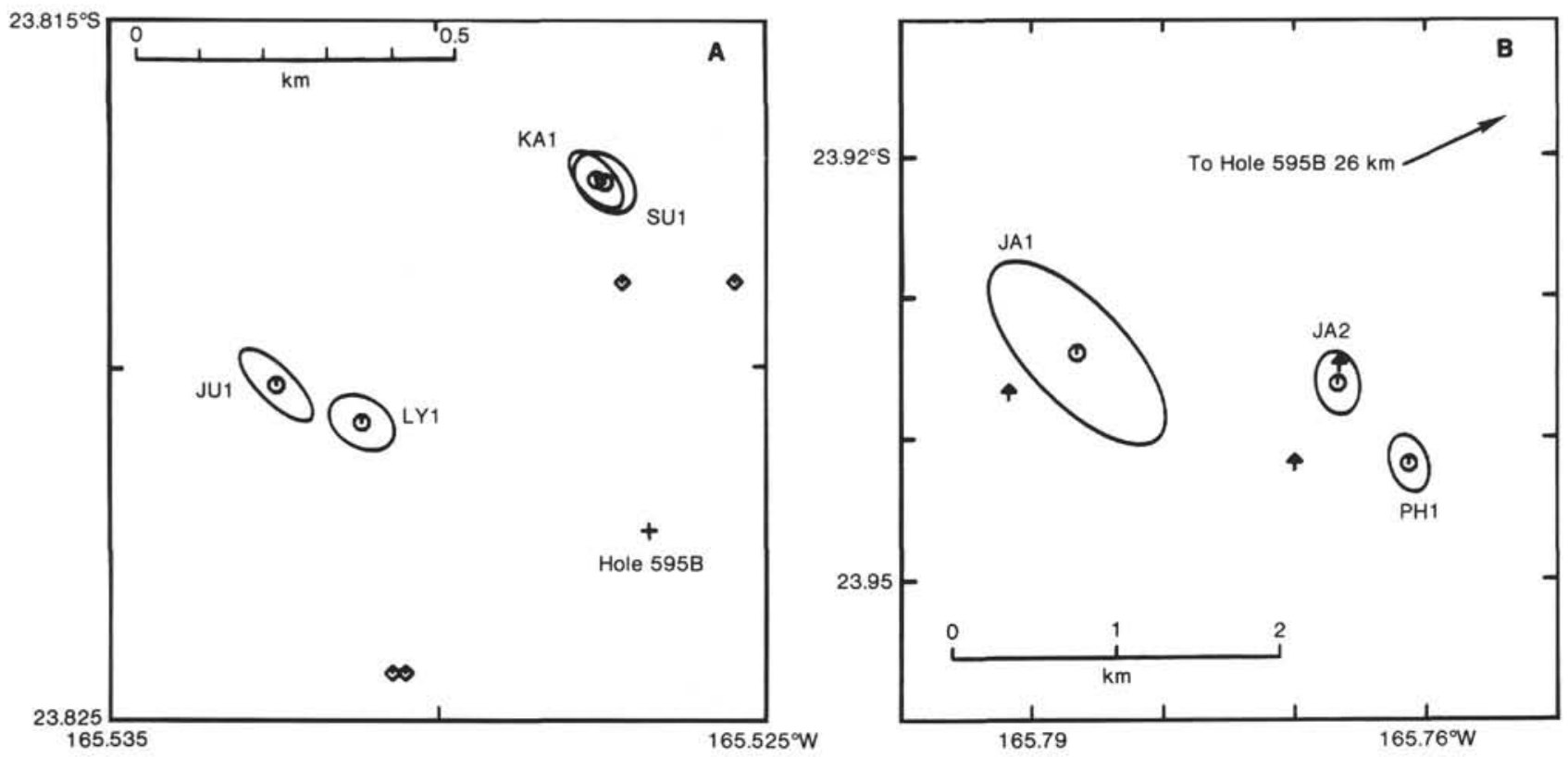

Figure 3. Locations of the MSS and six OBSs during the first phase of the Ngendei Experiment. See text for explanation of symbols. A. Configuration of the four capsules which recorded refraction signals (Juan, Karen, Lynn, and Suzy). B. Configuration of the two OBSs which concurrently recorded teleseismic signals in a triggered mode (Janice and Phred).
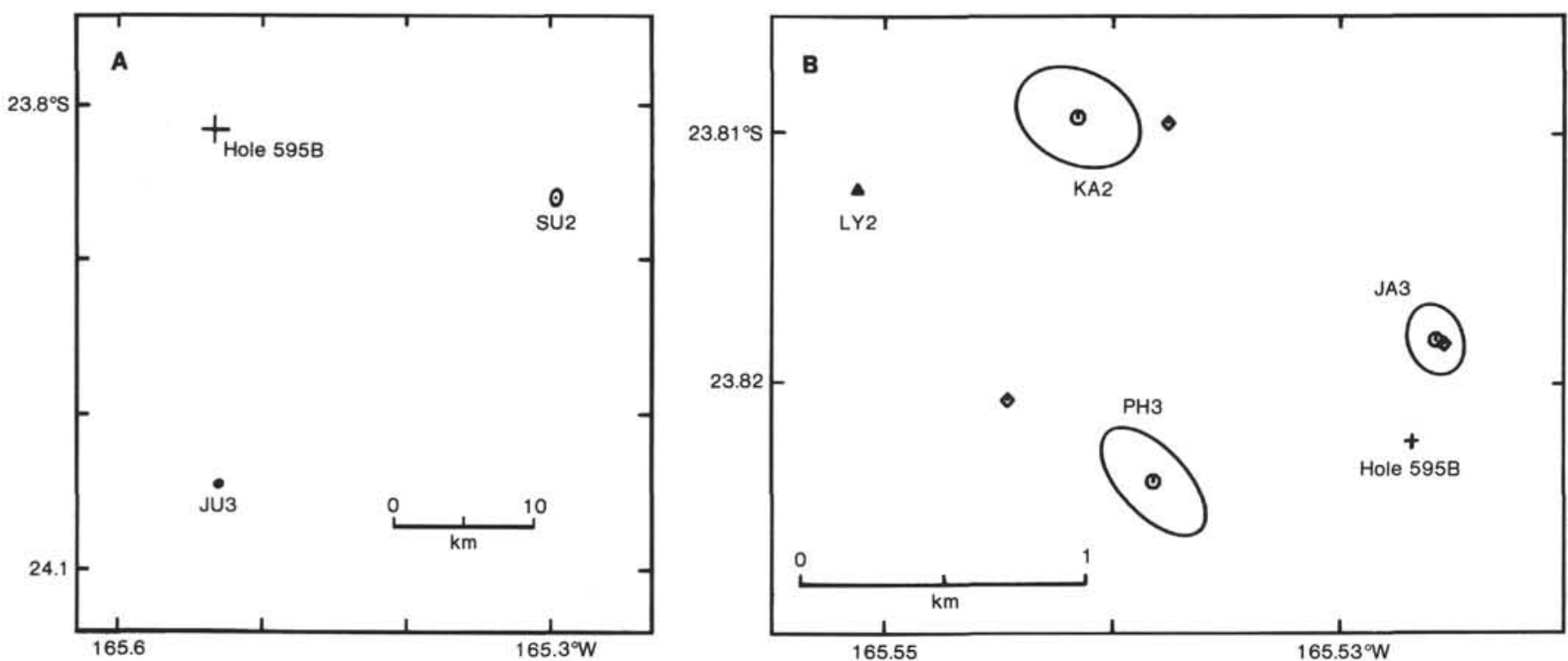

Figure 4. Locations of the MSS and OBSs during the second phase of the Ngendei Experiment. See text for explanation of symbols. A. MSS and 2 farthest OBSs. B. MSS and 4 nearest OBSs.

Table 1. OBS locations and characteristics during the Ngendei Experiment, first phase.

\begin{tabular}{|c|c|c|c|c|c|c|c|c|}
\hline \multirow{2}{*}{$\begin{array}{l}\text { OBS } \\
\text { site }\end{array}$} & \multirow[b]{2}{*}{ Lat. $\left({ }^{\circ} \mathrm{S}\right)$} & \multirow[b]{2}{*}{ Long. $\left({ }^{\circ} \mathrm{W}\right)$} & \multicolumn{2}{|c|}{ Deployed $^{\mathrm{a}}$} & \multirow{2}{*}{$\begin{array}{c}\text { Depth } \\
\text { (m) }\end{array}$} & \multirow{2}{*}{$\begin{array}{l}\text { Range, } \\
\text { azimuth }^{\text {bim }} \\
\left(\mathrm{km},{ }^{\circ}\right)\end{array}$} & \multirow{2}{*}{$\begin{array}{c}\text { Response } \\
\text { type }\end{array}$} & \multirow{2}{*}{$\begin{array}{l}\text { Buffer } \\
\text { length } \\
\text { (s) }\end{array}$} \\
\hline & & & From & To & & & & \\
\hline $\mathrm{JA1}$ & 23.93398 & 165.78653 & $024: 0626$ & 029:0715 & 5704 & $29.18,245$ & Teleseismic & 58 \\
\hline JA2 & 23.93612 & 165.76627 & $032: 0455$ & 034:0815 & 5717 & $27.44,242$ & Teleseismic & 58 \\
\hline JU1 & 23.82024 & 165.53244 & $029: 1104$ & $040: 0535$ & 5618 & $0.62,292$ & Refraction & 13 \\
\hline KA1 & 23.81733 & 165.52758 & 029:0102 & 040:0807 & 5612 & $0.56,352$ & Refraction & 13 \\
\hline LY1 & 23.82077 & 165.53115 & $030: 1124$ & 041:0817 & 5603 & $0.47,292$ & Refraction & 13 \\
\hline PH1 & 23.94182 & 165.76130 & 023:0604 & 038:0850 & 5676 & $27.29,241$ & Teleseismic & 58 \\
\hline SU1 & 23.81737 & 165.52745 & 030:0039 & 041:0556 & 5612 & $0.56,353$ & Refraction & 13 \\
\hline
\end{tabular}

a Deployment dates in julian days, year 1983.

b Reference site is MSS location: $23.82233^{\circ}$ South, $165.52683^{\circ}$ West. Azimuth is clockwise from North. 
Table 2. OBS locations and characteristics during the Ngendei Experiment, second phase.

\begin{tabular}{|c|c|c|c|c|c|c|c|c|}
\hline \multirow{2}{*}{$\begin{array}{l}\text { OBS } \\
\text { site }\end{array}$} & \multirow[b]{2}{*}{ Lat. $\left({ }^{\circ} \mathrm{S}\right)$} & \multirow[b]{2}{*}{ Long. $\left({ }^{\circ} \mathrm{W}\right)$} & \multicolumn{2}{|c|}{ Deployed $^{\mathrm{a}}$} & \multirow{2}{*}{$\begin{array}{l}\text { Depth } \\
\text { (m) }\end{array}$} & \multirow{2}{*}{$\begin{array}{l}\text { Range, } \\
\text { azimuth }^{\mathrm{b}} \\
\left(\mathrm{km},{ }^{\circ}\right)\end{array}$} & \multirow{2}{*}{$\begin{array}{c}\text { Response } \\
\text { type }\end{array}$} & \multirow{2}{*}{$\begin{array}{l}\text { Buffer } \\
\text { length } \\
\text { (s) }\end{array}$} \\
\hline & & & From & To & & & & \\
\hline JA3 & 23.81823 & 165.52574 & $036: 1433$ & $081: 1520$ & 5605 & $0.47,14$ & Teleseismic & 58 \\
\hline JU3 & 24.04531 & 165.53030 & $042: 1124$ & $081: 1100$ & 5579 & $24.80,181$ & Teleseismic & 13 \\
\hline KA2 & 23.80939 & 165.54157 & $042: 2142$ & $082: 0600$ & 5593 & $2.08,314$ & Teleseismic & 58 \\
\hline LY $2^{\mathrm{C}}$ & 23.81230 & 165.55120 & $043: 1357$ & $082: 1040$ & 5503 & $2.72,294$ & Teleseismic & 13 \\
\hline PH2 & 23.82394 & 165.53820 & $040: 2045$ & 082:0950 & 5544 & $1.17,261$ & Teleseismic & 13 \\
\hline SU2 & 23.85997 & 165.29674 & $041: 2247$ & $081: 0531$ & 5654 & $23.77,100$ & Teleseismic & 58 \\
\hline
\end{tabular}

a Deployment dates in julian days, year 1983.

beference site is MSS location: $23.82233^{\circ}$ South, $165.52683^{\circ}$ West. Azimuth is clockwise from North.

c Drop location.

The OBSs recorded daily noise samples and triggered events.

Melville recovered the OBSs and the MSS ocean-bottom recorder during the final phase. It was discovered that the MSS recorder had ceased operations approximately two days after deployment because of a water leak in one of its battery spheres. Following a brief shipboard recording period, the mooring was redeployed with the load of the ocean-bottom recorder replaced by a concrete clump anchor. The instrumentation package was left in Hole 595B.

\section{DATA}

The following describes the recovered data and various instrument malfunctions which rendered some of these data unsuitable for analysis. Figures 5-7 schematically inventory the noise data.

\section{OBS Data}

A total of 1420 noise events were obtained from the OBSs; over half were simultaneous with MSS data, and most were recorded simultaneously by at least two capsules. Noise data were regularly recorded by the OBSs throughout the experiment. In particular, all capsules recorded noise samples at GMT midnight during the final phase. However, $70 \%$ of the OBS noise samples were originally scheduled as seismic refraction events. These samples were the serendipitous result of MSS deployment delays, which forced a drastic rescheduling of the refraction experiment, and of refraction shots which detonated late or not at all.

During the first phase of the Ngendei Experiment, four OBS data channels were defective. The gain-ranger malfunctioned in OBS Juan channels $\mathrm{Y}$ and $\mathrm{H}$ and OBS Lynn channel X, resulting in amplified noise amplitudes that often exceeded the digital word size ("clipped"). OBS Janice channel $\mathrm{H}$ suffered a periodic transient signal at intervals of one second.

Only two OBSs were defective during the second phase. The digitizer of OBS Janice channel $Z$ could not set bit 3 in addition to the persistent transient of its channel $\mathrm{H}$. Progressive tape head misalignment on OBS Juan rendered data recorded after 25 February 1983 inaccessible by playback instrumentation.

\section{MSS Data}

Totals of $119.5,83.25$, and $43.25 \mathrm{hr}$. of data were recovered from the Teledyne and Gould shipboard and

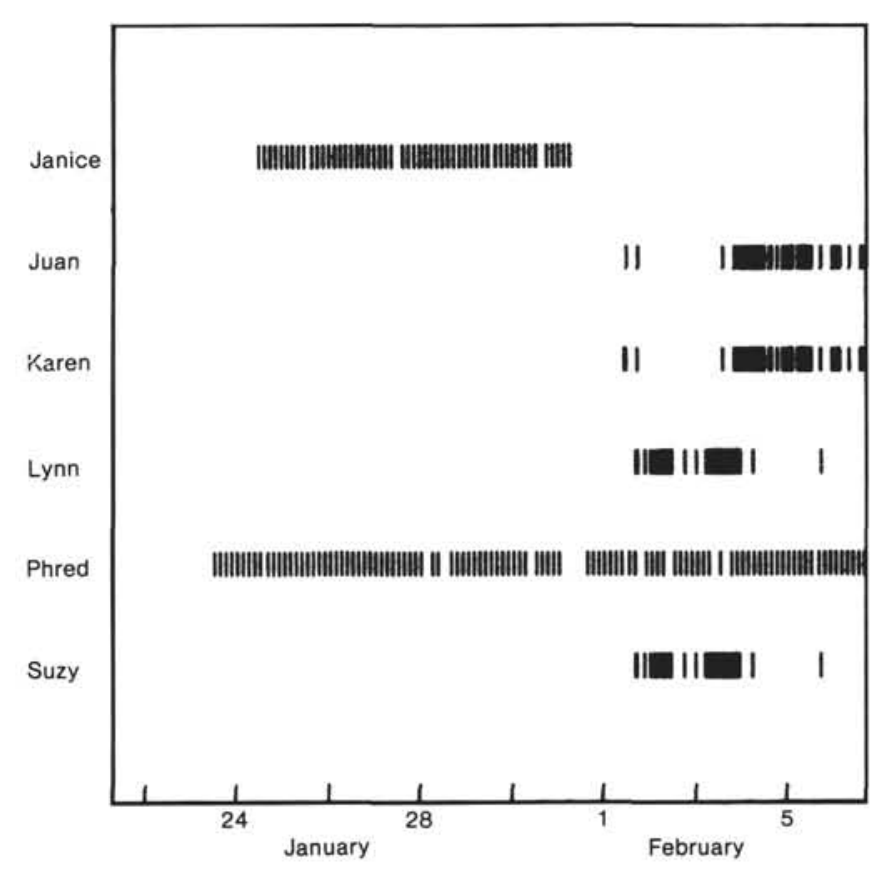

Figure 5. Chart of noise data available for analysis before the MSS began recording. The OBSs recorded discrete events, shown as vertical ticks. CUT date is given along the bottom axis, and capsule names on left.

ocean-bottom recorders, respectively. Most of the data were recorded aboard ship over the six-day period immediately following sensor emplacement in the borehole, when 114.25 and $70.5 \mathrm{hr}$. of data were obtained by the Teledyne and Gould systems. All of Refraction Line 5 and most of the outbound leg of Line 4 were recorded simultaneously by the MSS and OBSs. The missed outbound portion of Line 4, referred to as Line 6, was recorded only by the MSS at the very end of phase 1 , as the OBSs were being redeployed for the teleseismic experiment of phase 2 .

MSS data were recorded continuously except for interruptions for maintenance or because the system malfunctioned. The most notable malfunction was the total failure of the ocean-bottom recording system approximately two days after its deployment. In addition, MSS sensor Y malfunctioned throughout the experiment and yielded no usable data in either the mid- or short-period bands.

Gould channel SZ, the primary short-period verticalcomponent channel, was not recorded during most of 


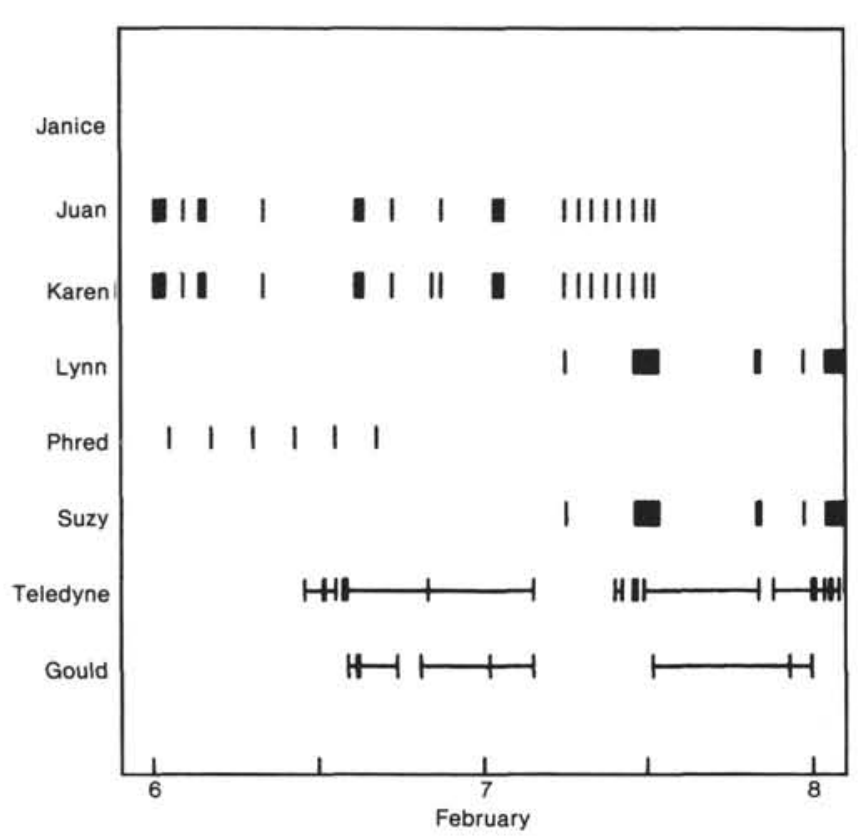

Figure 6. Noise samples recorded at about the start of MSS data recording. The MSS systems recorded continuously during the intervals shown with horizontal sediments bounded by vertical lines. MSS recording system and OBS names identified along the left.

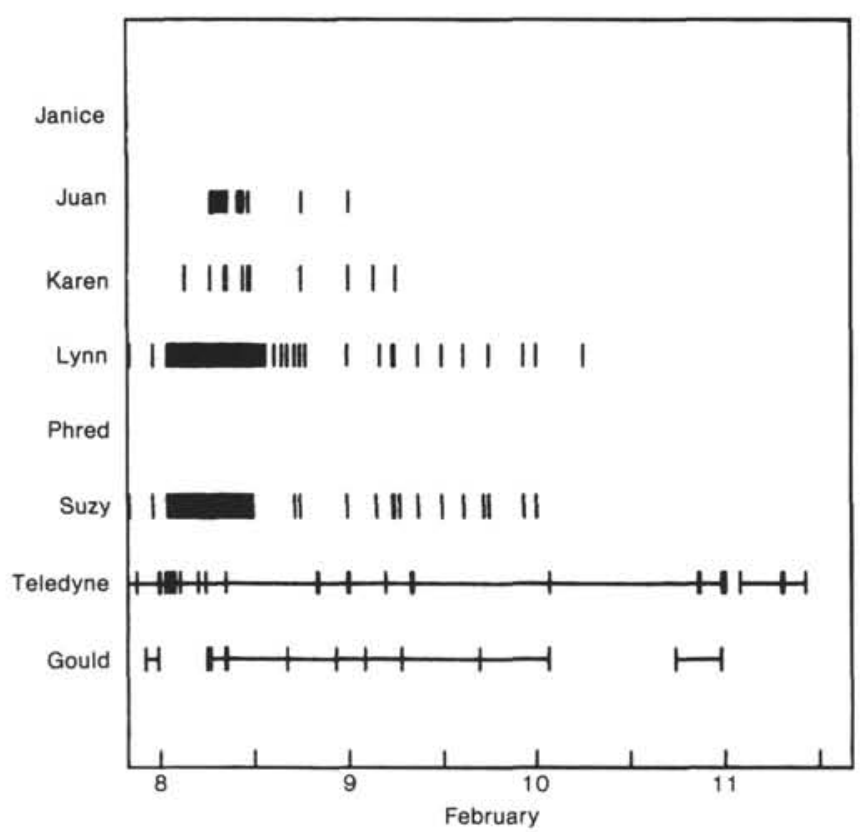

Figure 7. Noise samples recorded during the latter portion of the first phase of MSS operations. See caption of Figure 6 for explanation. MSS recording systems and OBS names identified along the left.

the shipboard periods of phases 1 and 3 because it suffered radio-frequency interference. Also, a Gould electronics bay in the borehole package which processed channel MZ and initiated calibrations failed at the start of the second phase and never resumed operations. Teledyne channel MZ, of course, was not affected by this malfunction.

\section{Quality}

Data quality and valid frequencies of microseismic noise measurement were assessed with both time- and spectral-domain criteria. In particular, power density and coherence estimates were computed in the manner described by Welch (1967). Spectra are obtained from demeaned, nonoverlapping data segments tapered with a normalized Hanning window using a mixed-radix Fast Fourier Transform algorithm (Singleton, 1969) which does not require power-of-two data lengths. Stable spectral estimates are then formed from averages of cross- and auto-spectra. Spectra are normalized so that the total power per Nyquist-frequency bandwidth is equal to the time-domain variance, which essentially folds the energy of the negative frequencies into that of the positive.

Figures 8 and 9 show a typical example of multichannel MSS data from the Teledyne and Gould systems, respectively, recorded during the shipboard recording period. (Plot scales were chosen to show background noise levels, with the result that large-amplitude signals appear clipped in this figure.) Y-sensor malfunction is evident from both figures. Note that Gould channel SZ (Fig. 9) is disabled, as explained earlier. The high-frequency content of Teledyne and Gould short-period signals is mostly ship-generated by Challenger.

Proper representation of the data was investigated by computing relative timing and amplitudes between the two recording systems with cross-correlations and linear regressions of corresponding channels (Fig. 10). Typically, data from all short-period and mid-period Gould channels led the corresponding Teledyne data by 15 or 16 samples and were approximately 5.5 times greater in amplitude rather than 8 times, as we could expect from their different dynamic ranges ( 24 and 21 bits, respectively); the consequence is a $3 \mathrm{~dB}$ uncertainty in spectral estimates. Comparisons of data timing with independent time code (WWV) written adjacent to Teledyne data on strip-charts indicate that Gould's timing is in error. Teledyne sensor calibrations (Fig. 11) of properly functioning channels are within their expected norms by less than $4 \mathrm{~dB}$, suggesting that Gould amplitudes are in error. However, the calibration loop excludes portions of the total seismograph circuitry so this discrepancy cannot be verified. The departure of the MY and SY calibrations from the norms further demonstrates sensor malfunction. Note that the other mid-period channels depart drastically from the norm below approximately 0.2 $\mathrm{Hz}$.

Figure 12 compares power spectral density estimates of simultaneous vertical-component Teledyne and Gould data with instrument noise spectra. The data are not corrected for instrument response. The peaks above 8 $\mathrm{Hz}$ in the SB spectra (Fig. 12B, C) are ship-generated. Peaks in the SB Teledyne spectrum (Fig. 12C) which are absent in the short-period Gould spectrum (Fig. 12B) are manifestations of Teledyne aliasing. However, both Gould and Teledyne spectra have comparable values near the Nyquist frequency, implying that the Gould SB digital low-pass filter was not functioning properly. 
R. G. ADAIR, J. A. ORCUTT, T. H. JORDAN

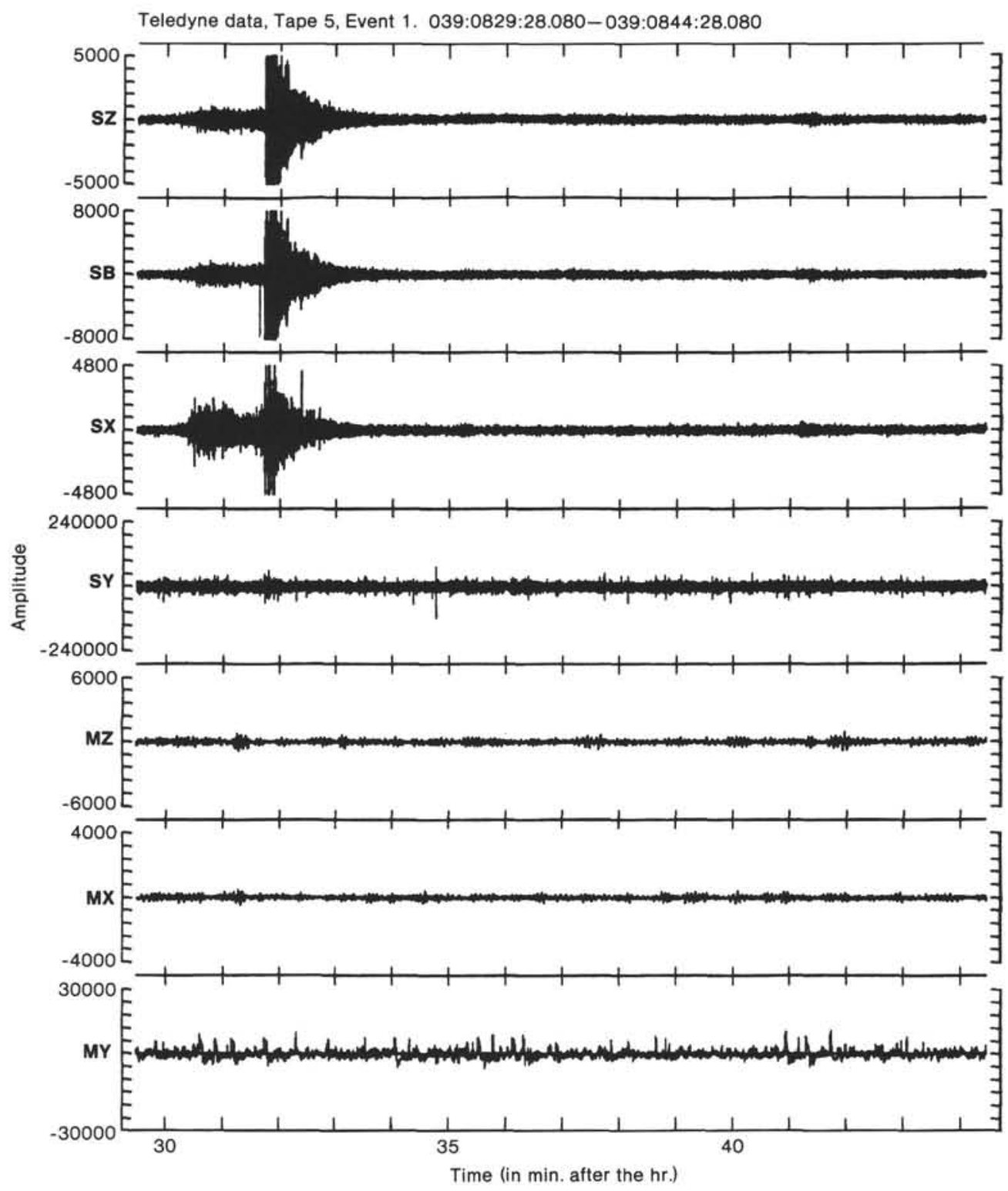

Figure 8. Typical example of seven-channel data from the Teledyne system. Channel identifications and amplitudes, in digital counts, along the left. The event number is arbitrary.

Also shown in Figure 12 are estimates of system noise (dashed lines), provided by H. B. Durham of Sandia Laboratories. The system noise is not significant over the entire short-period passband for either Teledyne or Gould data. The white spectrum of quantizing noise for the Teledyne data, from the uniformly distributed roundoff errors of digital representation (see, e.g., Bendat and Piersol, 1971, pp. 231-232), has a level near $10^{-2}$ counts $^{2} / \mathrm{Hz}$, well below the Teledyne signal level. Estimates of the Gould digitizing noise level are not available. Differences at frequencies greater than $4 \mathrm{~Hz}$ are probably due to the combined effects of aliasing and actual signal differences over the $175.5-\mathrm{cm}$ sensor separation. The MZ spectra (Fig. 12A) are similarly untainted by system and sampling noise, and, furthermore, have sufficient frequency response roll-off at the high end to avoid aliasing.
Spectral coherences further delineate frequencies usable for earth noise estimates. Mid-period coherences (Fig. 13A) typically exceed 0.95 below the Gould low-pass filter knee at $1.5 \mathrm{~Hz}$ except at $1 \mathrm{~Hz}$, where it drops sharply over a very narrow band of frequencies. The sharp drop is due to energy present in the Gould data but not the Teledyne, and may be related to the Gould digitizing scheme. Gould and Teledyne SB coherence (Fig. 13B) exceeds 0.8 between approximately 0.2 and $4.0 \mathrm{~Hz}$. The coherence at higher frequencies declines amidst peaks caused by ship-generated signals. The sharp drops at approximately 2 and $4 \mathrm{~Hz}$ are similar to that at $1 \mathrm{~Hz}$ in the midperiod coherence. The frequencies bounding the shortperiod band of high coherence varied a great deal during the MSS deployment, but generally were those shown in Figure 13B. Coherence estimates between SB and SZ Teledyne data (Fig. 13C) were similar. In Figure 13, the 


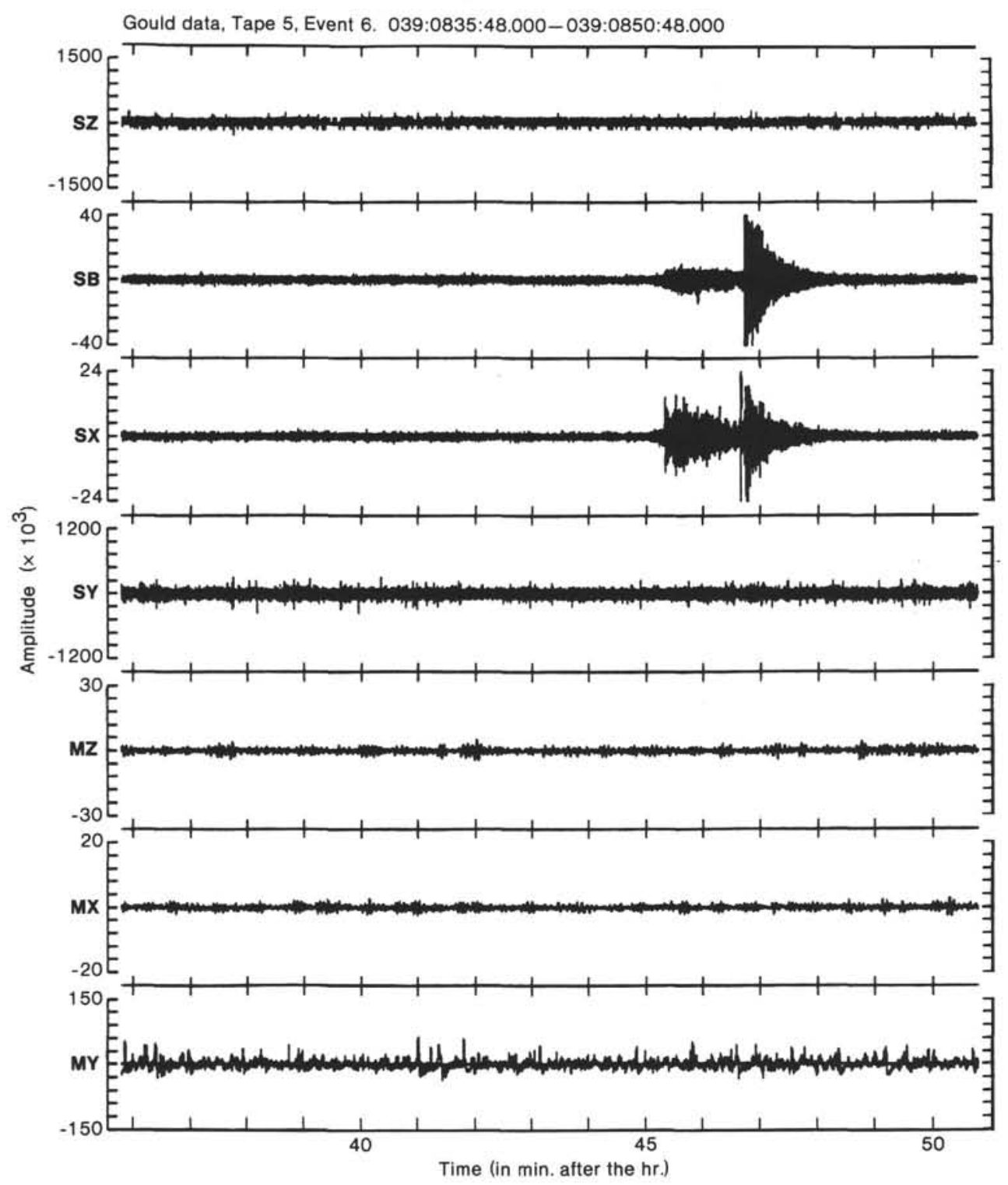

Figure 9. Typical example of seven-channel data from the Gould system during the first phase of MSS operations. Channel identifications and amplitudes, in digital counts $\left(\times 10^{3}\right)$ along the left. The event number is arbitrary.

level below which the coherences do not significantly differ (at the $95 \%$ confidence interval) from zero is shown with dashed lines.

Figure 14 plots typical 4-channel OBS data collected from a capsule employed to record refraction signals. In this figure, ship-generated noise dominates high frequency features on all channels. Since the OBSs have no redundant sensors, frequencies dominated by system and instrument noise cannot be estimated from channel coherence.

The OBS dynamic range and resolution are modest compared to those of the MSS systems, and, consequently, limitations imposed by the sampling noise are more severe in data recorded by the OBSs. As previously noted, two OBS instrument responses were employed during the Ngendei Experiment. Since the refraction response is more sensitive than the teleseismic response at high frequencies (see Fig. 1B), the latter will be more limited at lower frequencies. This is evident in Figure 15, which compares ambient and sampling noise estimates obtained with the two responses. The noise samples were not simultaneous. Although most of the data composing the teleseismic-filter spectrum (solid upper curve) were recorded after ship departure, its spectral levels exceed ship noise levels measured with a refraction filter (dashed lower curve) at most frequencies. In the teleseismic spectrum, sampling noise clearly dominates at frequencies greater than $15 \mathrm{~Hz}$, and is probably significant in the range $7-18 \mathrm{~Hz}$.

Ship-generated noise was estimated on a case-by-case basis because it depended on which ship was proximal to an instrument and ship speed and activity. However, in general ship noise spectra were characterized by sharply distinct peaks superimposed on a broadband level. The frequencies of most of the peaks were multiples of some fundamental, implying that the peaks were due to cavi- 

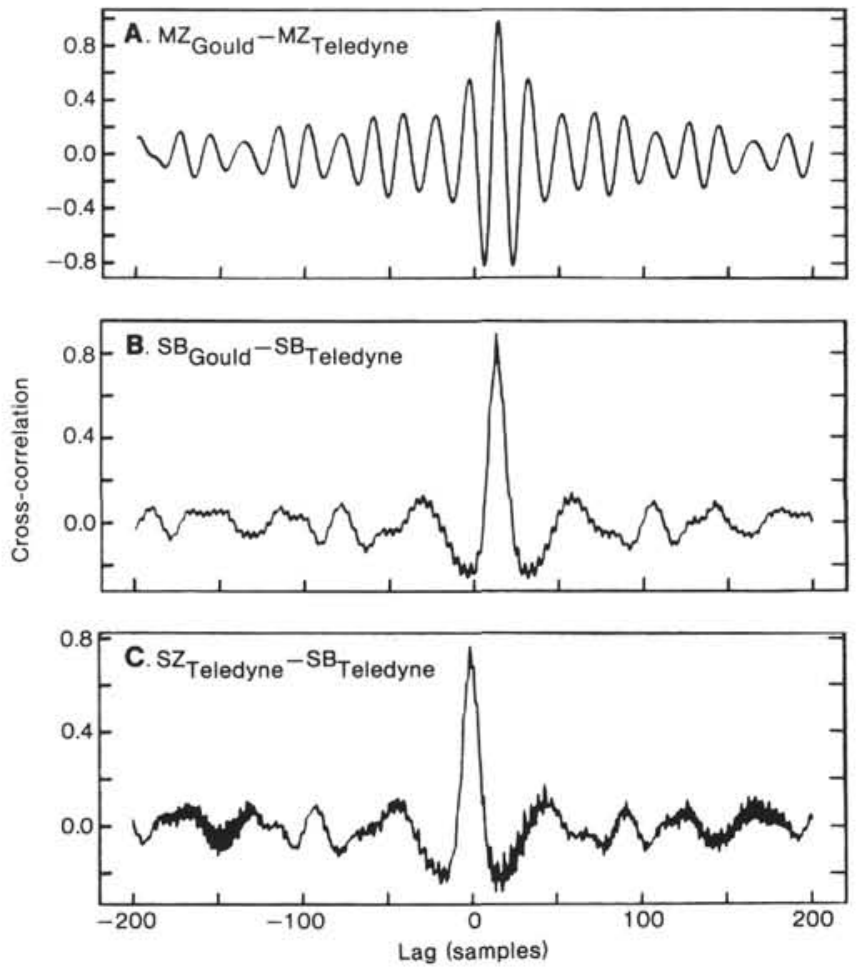

Figure 10. Cross-correlations of various channels of the Teledyne and Gould systems. A positive lag corresponds to the second-named channel in the figure label being late with respect to the first named channel. A. Cross-correlation between Gould and Teledyne channels MZ. B. Cross-correlation between Gould and Teledyne channels SB. C. Cross-correlation of Teledyne's primary and backup SP vertical-component channels.

tation by ship propellers (e.g., Urick, 1983). Challenger generated peaks at multiples of $10 \mathrm{~Hz}$ while maintaining station. Two other peaks at approximately 6.5 and 7.5 $\mathrm{Hz}$ were generated while it was under way. Peaks due to Melville were at multiples of 6 and $9 \mathrm{~Hz}$.

Figure 16A compares vertical-component power density spectra, corrected for gain but not instrument response, of OBS Phred data recorded before (solid curve) and after (dashed curve) both ships departed. The capsule, located $1.6 \mathrm{~km}$ west of the borehole, employed the teleseismic response. The measurement prior to ship departure was made at $0000 \mathrm{Z}, 12 \mathrm{Feb} 1983$, with both Challenger and Melville hove to within $2 \mathrm{~km}$ of the OBS. In this instance, ship-generated noise clearly dominates the spectrum at all frequencies above approximately $4.5 \mathrm{~Hz}$. After ship departure, least-count noise dominated above $7 \mathrm{~Hz}$, although the lowest frequency at which it dominated varied by $\pm 1 \mathrm{~Hz}$ because its level depends on OBS gain.

Some ambiguity exists concerning ship noise in the MSS data. Because the ocean-bottom recording system failed two days after its deployment, when Challenger was $13 \mathrm{~km}$ away drilling Hole 596 and Melville was en route to Tahiti, MSS noise measurements in the absence of ships are not available. However, Challenger was briefly silent ca. 0510Z, 13 February, while monitoring an ocean-bottom navigational transponder, thus providing a sample of low ship noise for the MSS. The MSS spectrum of this time period is compared in Figure 16B with that of data observed a short time later when Challenger began using the thrusters of its dynamic positioning system. Also shown in Figure 16B is an estimate of shortperiod system noise which has been scaled to fit the "quiet" spectrum. The good fit suggests that above 7 $\mathrm{Hz}$ system noise dominates the spectrum.

The abrupt change of slope in the spectra of Figure 16 is diagnostic of ship noise. On this basis, it is apparent from these and other spectra that ship noise may be important at frequencies as low as $3 \mathrm{~Hz}$ in both the OBS and MSS data.

The lowest valid frequency of OBS microseismic measurements is taken to be $0.1 \mathrm{~Hz}$. At lower frequencies, least-count and system noise dominate. The latter source of noise was inferred from the lack of estimate stability with regard to the number of spectra averaged in the power density estimates.

Thus, in summary, reliable spectral estimates of ambient seismic noise are available from MSS mid-period data between 0.2 and $1.5 \mathrm{~Hz}$; from MSS short-period data between 0.2 and $7 \mathrm{~Hz}$; and from OBS data between 0.1 and $7 \mathrm{~Hz}$. These bands are subject to the variability just described that arises from the proximity of the ship, and OBS gain range and instrument response. At frequencies greater than $7 \mathrm{~Hz}$, sampling noise dominates OBS teleseismic data, so that lower bounds on oceanbottom microseismic noise levels must be established using data recorded with the refraction response.

\section{RESULTS AND DISCUSSION}

The primary objectives of the noise analysis are the comparison of noise levels recorded by the OBS and MSS sensors, and the investigation of noise generation and propagation in the deep sea. Given the hypothesis that high-frequency $(0.14-10 \mathrm{~Hz})$ microseismic noise is composed principally of interface waves trapped near the seafloor/ocean-bottom boundary, substantially lower noise levels are anticipated at the MSS. This hypothesis is supported by results from the Leg 78B MSS deployment (Adair et al., 1984).

Figures 17 and 18 show typical spectral estimates, corrected for instrument response, of simultaneous MSS and OBS observations in units of $\mathrm{nm}^{2} / \mathrm{Hz}$. The data were collected over a $70 \mathrm{~min}$. period commencing $0840 \mathrm{Z}, 8$ February 1983 . The estimates are averages of 10 individual spectra. Each OBS spectrum was computed from $13.02 \mathrm{~s}$ of data, whereas each MSS spectrum is a composite of mid-period and short-period spectra computed from, respectively, 128 and $12.8 \mathrm{~s}$ of Gould system data. The midperiod spectrum is shown at frequencies less than $1.4 \mathrm{~Hz}$ to achieve high-frequency resolution with a minimum of computation. The Gould spectral amplitudes have been adjusted by $3 \mathrm{~dB}$ to compensate for the digital amplitude mismatch described above.

While the data of Figures 17 and 18 were collected, the OBS (Suzy) was $0.6 \mathrm{~km}$ north of the MSS site, Challenger maintained station approximately $1.5 \mathrm{~km}$ northwest of the borehole, and Melville was completing Refraction Line 5 more than $170 \mathrm{~km}$ northwest of the borehole. Ship noise for all these spectra dominated at frequencies greater than $4.5 \mathrm{~Hz}$. 

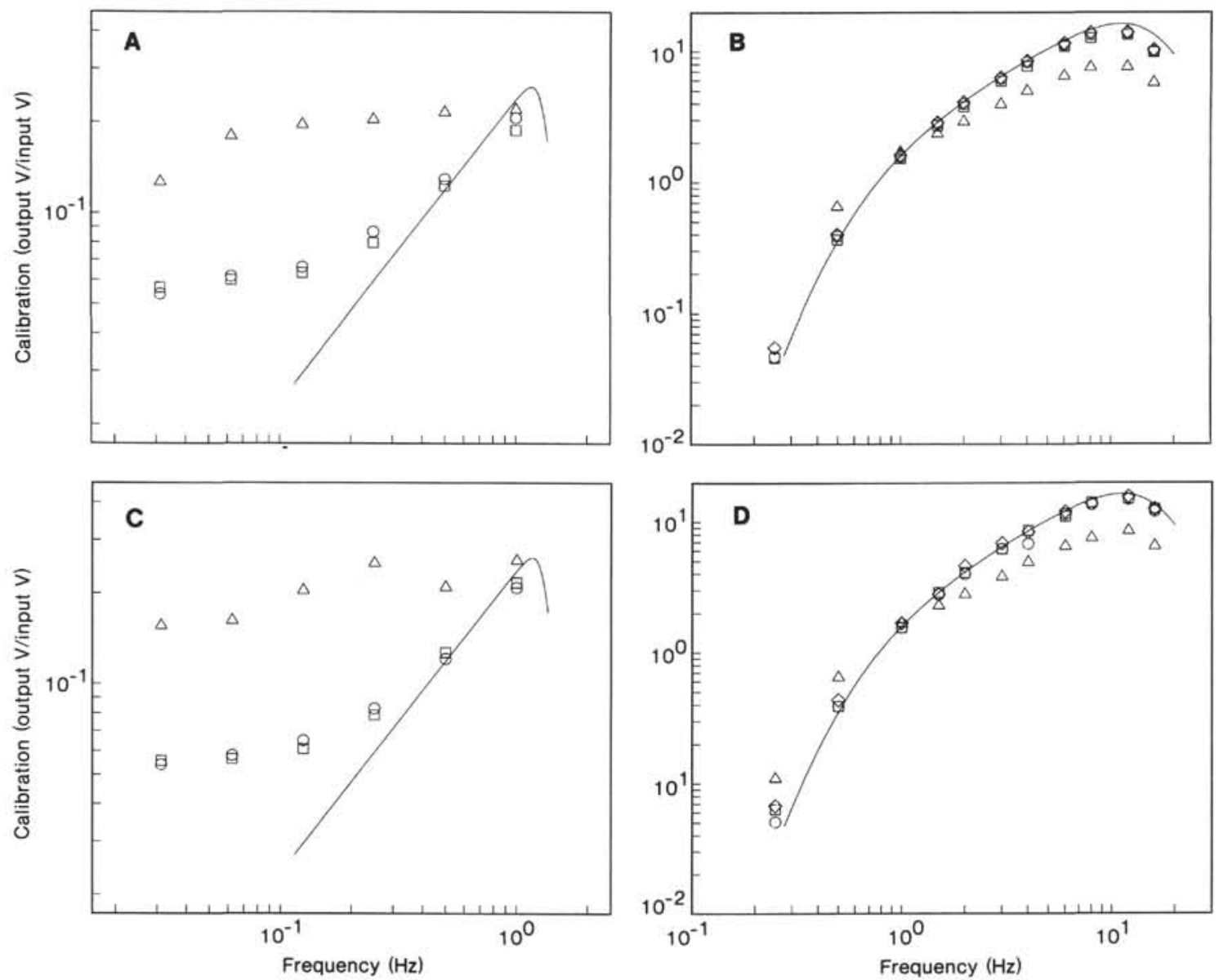

A, C: $\square M Z ; O M X ; \triangle M Y$

B, D: $\square S Z ; O S X ; \triangle S Y ; \diamond S B$

Figure 11. MSS sensor calibrations recorded by the Teledyne system during the first phase of the Ngendei Experiment for (A) midperiod and (B) short-period channels, and during the last phase for (C) midperiod and (D) short-period channels.

Differences between two spectra are significant at the $95 \%$ confidence level if they exceed $5.5 \mathrm{~dB}(-2.3$ and $+3.2 \mathrm{~dB}$ ). This assumes that the spectra are derived from identically distributed normal processes, so that each estimate is $\chi^{2}$-distributed with $2 n$ degrees of freedom, where $n=10$, the number of spectra averaged (Bendat and Piersol, 1971). For comparison, the $90 \%$ confidence interval is $4.7 \mathrm{~dB}$.

The spectra have the usual overall appearance of earth noise in this frequency band. They fall off rapidly toward higher frequencies from the microseism peak, which typically lies between 0.1 and $0.3 \mathrm{~Hz}$. The ubiquitous microseism peak is generated by the nonlinear interaction of ocean surface waves having the same frequency but traveling in opposite directions (Longuet-Higgins, 1950). This interaction produces ocean-bottom pressure fluctuations that oscillate at twice the frequency of the generative surface waves. Although no wave spectrum data are available for the Ngendei Experiment, a qualitative description may be obtained from the deck and weather logs of Challenger. Swell periods of 6, 7, 9, 10, and $12 \mathrm{~s}$ were reported during the $4 \mathrm{hr}$. which preceded and followed the noise observations of Figures 17-18. This corresponds to a double-frequency range of 0.17 -
$0.33 \mathrm{~Hz}$, which is roughly the band of the observed microseism peak.

At the microseism peak (approximately $0.2 \mathrm{~Hz}$ ), levels at the seafloor and in the borehole on all components were within $5 \mathrm{~dB}$ of each other. In the band 0.6$4.5 \mathrm{~Hz}$, vertical OBS levels exceeded those on the MSS by $10-15 \mathrm{~dB}$ (Fig. 17), and horizontal OBS levels exceeded the MSS levels by $25-30 \mathrm{~dB}$ (Fig. 18). This contrasts with results from Leg 78B (Fig. 19), in which verticalcomponent ocean-bottom levels observed $2 \mathrm{~km}$ from the MSS site exceeded borehole levels by $10 \mathrm{~dB}$ at the microseism peak. Whereas the distances between the OBS and MSS were comparable for these two MSS deployments, the sensor was much more deeply buried $(519 \mathrm{~m}$, with basement rock overlain by $93 \mathrm{~m}$ of sediment) on Leg 78B, suggesting that the depth of the Leg 91 sensor was insufficient to achieve a significant reduction of noise levels at the microseism peak. It was, however, apparently adequate at higher frequencies.

The irregular fall-off of the microseismic noise in Figures $17-18$, at $60-80 \mathrm{~dB} /$ decade, is punctuated by several peaks and slope breaks. These spectral characteristics are due to the combined influences of the source spectrum and the seafloor elastic structure. The princi- 

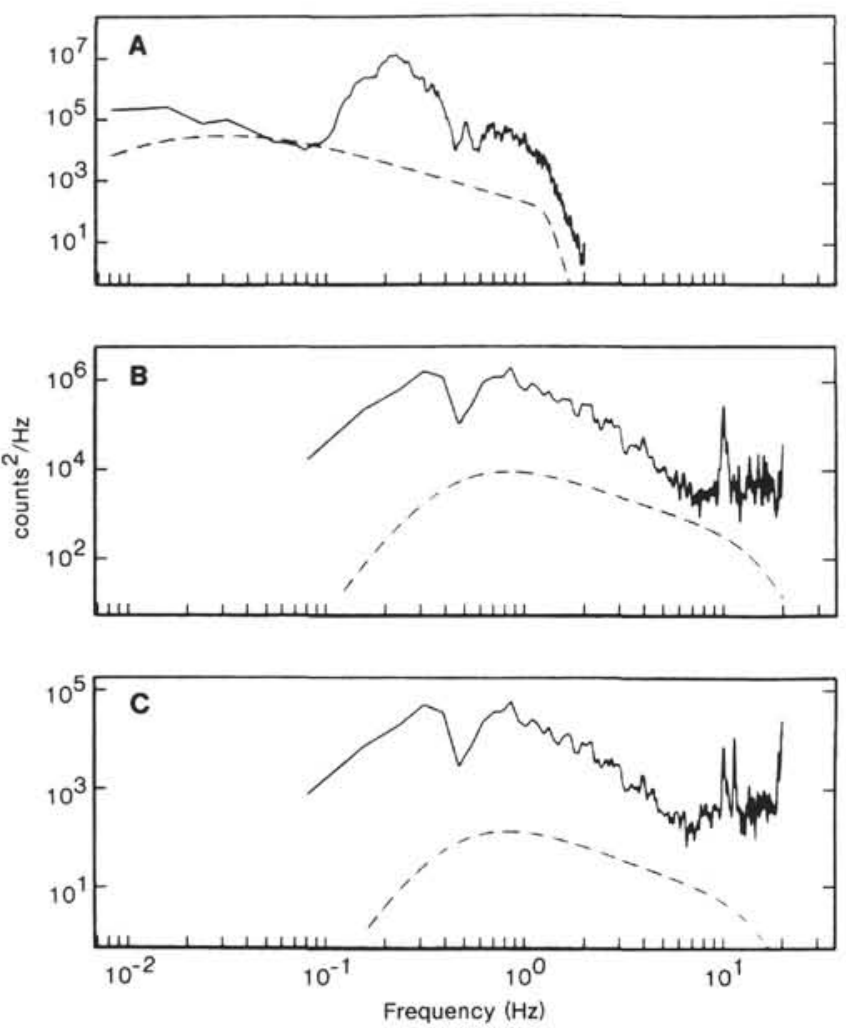

Figure 12. Spectral power density estimates of typical MSS noise samples compared to system noise levels. The spectra, given in counts ${ }^{2} /$ $\mathrm{Hz}$, have not been corrected for instrument response. A. Gould channel MZ. B. Gould channel SB. C. Teledyne channel SB.

pal source of the noise in the open ocean may reasonably be assumed to be pressure fluctuations acting at the seafloor (Webb, 1984; Hasselmann, 1963; Longuet-Higgins, 1950). At a given frequency, the power density would include contributions from a normal mode of the seafloor-ocean structure to the degree that the source excites it. Therefore, spectral peaks may be due to peaks in the source spectrum or to the resonant forcing of one or more seismic normal modes.

Webb (1984) predicts a fall-off of $70 \mathrm{~dB} /$ decade in ocean-bottom pressure noise at these frequencies when the source is due to the pressure effects of the nonlinear interaction of persistent wind waves in the "equilibrium" spectrum. The spectrum of ocean-bottom pressure (Fig. 20) measured concurrently with the displacement spectra of Figures 17-18 did not fall off in a power-law way. At frequencies near $1 \mathrm{~Hz}$, the slope is -7 (see Fig. 20), suggesting that the source was not the equilibrium windwave forcing in this instance. The slope breaks at approximately 2 and $4 \mathrm{~Hz}$ and the flattening between 6 and $15 \mathrm{~Hz}$ (more obvious in spectra lacking local ship noise; see Fig. 21) may correspond to distant shipping noise (Urick, 1983), as it does in the heavy traffic of the North Atlantic.

The characteristic fall-off of pressure noise from the microseism peak is reported to be on the order of 30 $\mathrm{dB} /$ decade (Urick, 1983), much less than was observed at the Ngendei site. This lower value may be due to the coarse bandwidths typically employed in computing spectral measurements and to changing wave fields during the
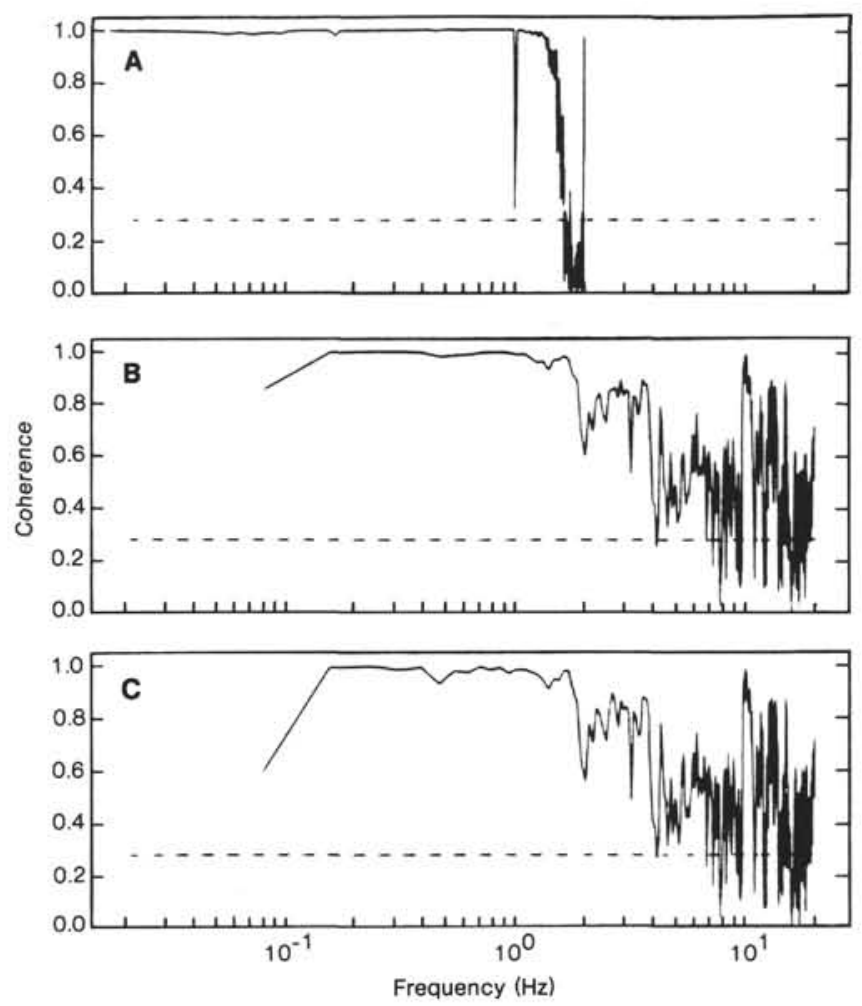

Figure 13. Coherence spectra between (A) aligned Teledyne and Gould channel MZ, (B) aligned Teledyne and Gould channel SB, and (C) Teledyne channels SZ and SB. The dashed line depicts the $95 \%$ confidence level that the coherence is not different from zero.

period of spectral averaging, especially changes in direction. Figure 21 compares three high-resolution, oceanbottom pressure spectra, reported by Nichols (1981), to an average of 39 daily, 58-s samples of pressure observed on OBS Suzy between 12 February and 22 March, 1983. The two spectra collected by Talpey and Worley were measured in $4.3 \mathrm{~km}$ of water near Bermuda, and the Eleuthera spectra in $1.2 \mathrm{~km}$ of water. Differences between the Talpey-Worley spectra were attributed to local wind speeds. The spectra of Figure 21, in particular the OBS and Talpey-Worley spectra, have a similar shape between 0.2 and $10 \mathrm{~Hz}$. The lower Eleuthera spectral levels near the microseism peak were apparently due to the shallower observation depth.

The relationship between different components of the noise at the MSS site contrasts with that at the OBS site. Vertical MSS levels uniformly exceeded the horizontal levels (Fig. 22) by $4 \mathrm{~dB}$ whereas vertical OBS levels were 10-20 dB lower than the horizontal levels (Fig. 23) at frequencies greater than the frequency of the microseism peak. Since horizontal and vertical amplitudes and their ratios vary differently with depth for different interface wave modes (Latham and Sutton, 1966; Latham and Nowroozi, 1968), this observation is consistent with the surface wave mode of noise propagation. For realistic models of the seafloor structure which include a sediment layer, the fundamental mode interface wave, at typical microseism peak frequencies, exhibits horizontal motion on the order of four times the amplitude of vertical motion at the seafloor, and comparable amplitudes 
Channel VERT

MAX: $3.60 E+00$

$Y$-TIC $0.5 E+00$

$<\mathrm{Y}>$ :-2.52E-02

No filter
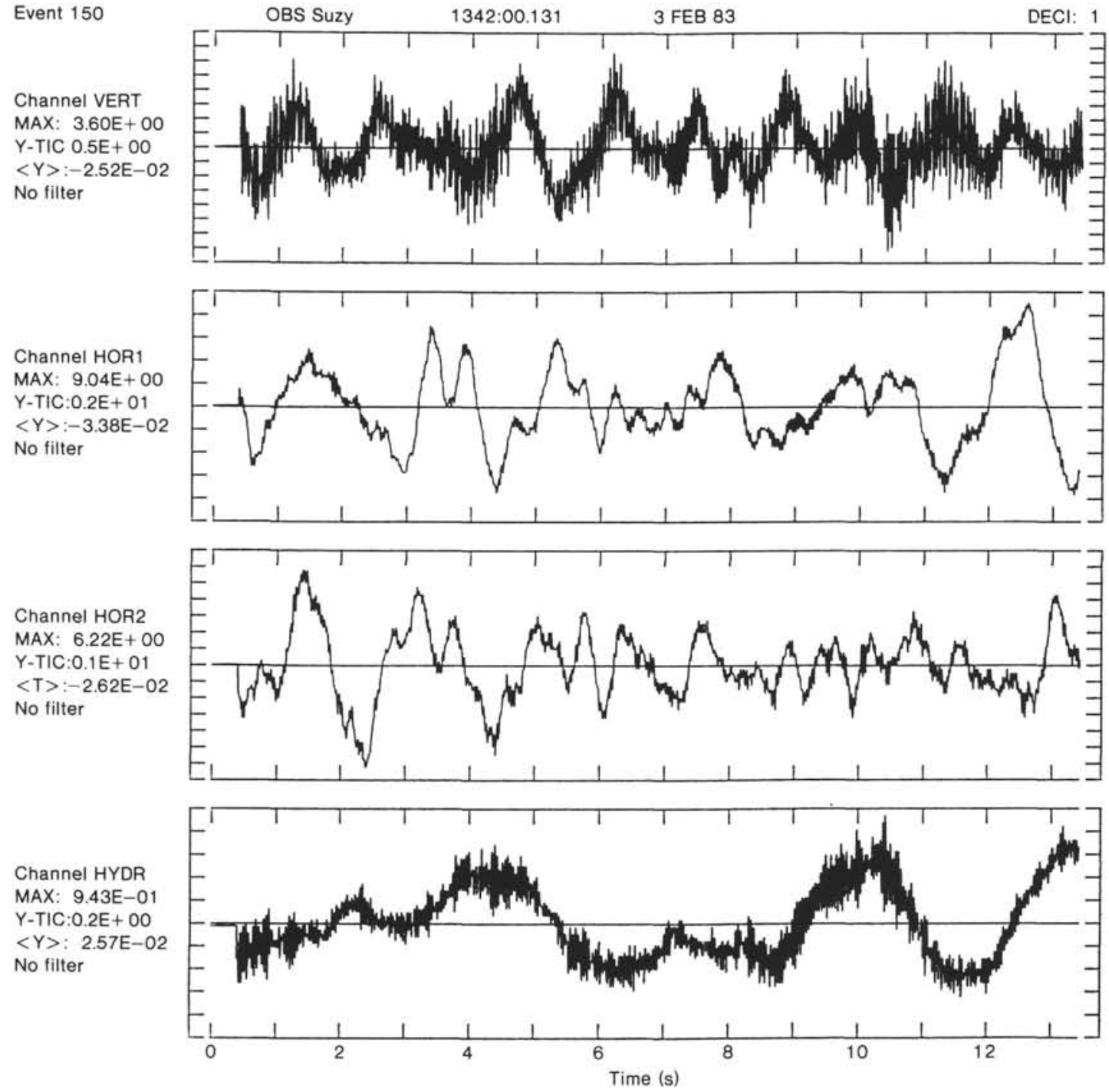

Figure 14. Example of 4-channel OBS data recorded with the refraction instrument response. Data are from OBS Suzy. Amplitudes are given in gain-corrected counts and each channel's plot has been individually scaled. Channels are, from top to bottom, vertical, two horizontals, and hydrophone.

for the two components within competent basement rock (Latham and Sutton, 1966). Future analysis of the Ngendei noise data will model these observations to further constrain the propagation mode of the noise.

The microseism peak and a $0.4 \mathrm{~Hz}$-wide band centered at $1 \mathrm{~Hz}$ display high coherence and a cross-phase of approximately $180^{\circ}$ (Fig. 24A and B) between the pressure and vertical displacement. It may be shown that at a fluid-solid interface, kinematic boundary conditions require a $180^{\circ}$ phase shift for both normally incident plane waves reverberating in the water column (Schneider and Backus, 1964) and for trapped modes of the oceanseafloor elastic system (Bradner, 1962; Schneider et al., 1964; Latham and Sutton, 1966). For plane waves, the pressure-seismic velocity ratio is constant with frequency and equals the product of density $\rho$ and acoustic speed $\alpha$ in the water, $1.5 \times 10^{6}$ in MKS units, whereas for trapped modes it may vary with frequency and exceed $\rho \alpha$ (Bradner, 1962; Latham and Nowroozi, 1968). Figure 24C plots the ratio between the pressure and vertical-compo- nent velocity power density spectra, normalized by $(\rho \alpha)^{2}$. Over the two bands of high coherence, this ratio is on the order of 10 , rather than one, suggesting that in this instance the bands represent trapped seismic modes. Thus, in this case, the practice of comparing seismic ground velocities $V(f)$ to a "plane-wave equivalent" pressure $P(f)$ via the relation $P=\rho c V$ is quite incorrect.

Coherences between OBS capsule pairs were computed to investigate noise field propagation. Figure 25 shows the coherence and cross-phase between the vertical and hydrophone channels of OBSs Suzy and Lynn, separated by $0.6 \mathrm{~km}$, for the same time interval as above. Again, energy at the microseism peak is highly coherent. The cross-phase at these frequencies is not significantly different from zero, implying either simultaneous arrival of microseism energy at the two capsules or a wavelength much larger than the capsule separation. Latham et al. (1967) calculate the dispersion curves for trapped modes in an ocean-bottom structure similar to that of the Ngendei site. At these frequencies the fundamental 


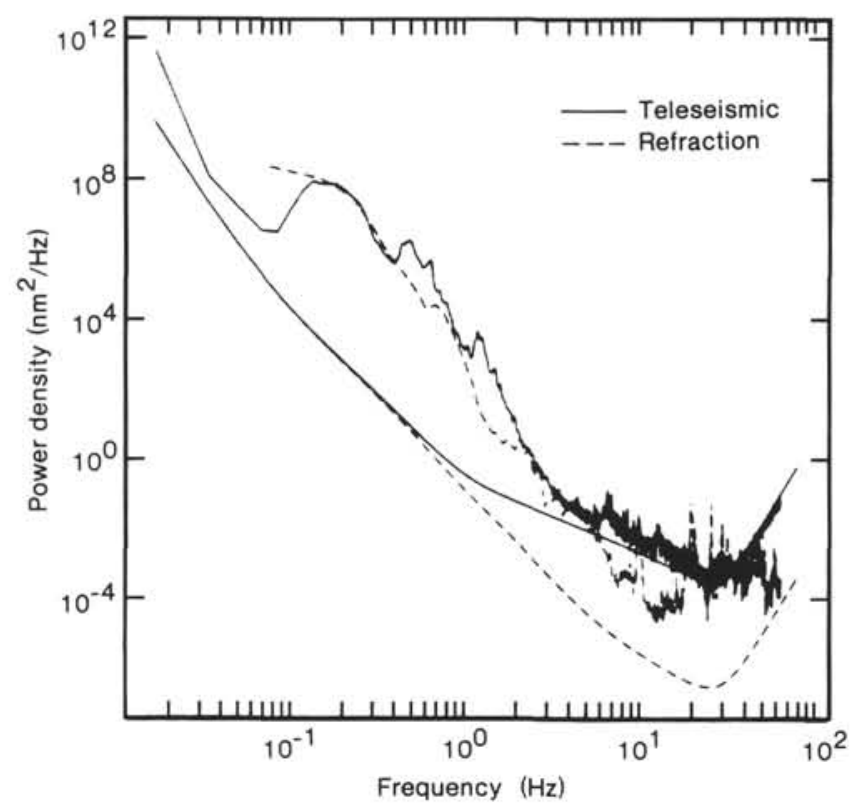

Figure 15. Comparison of noise spectrum obtained with the teleseismic (solid upper curve) and refraction (dashed upper curve) OBS responses. The corresponding instrumentally corrected sampling noise spectra (lower curves) are also shown.

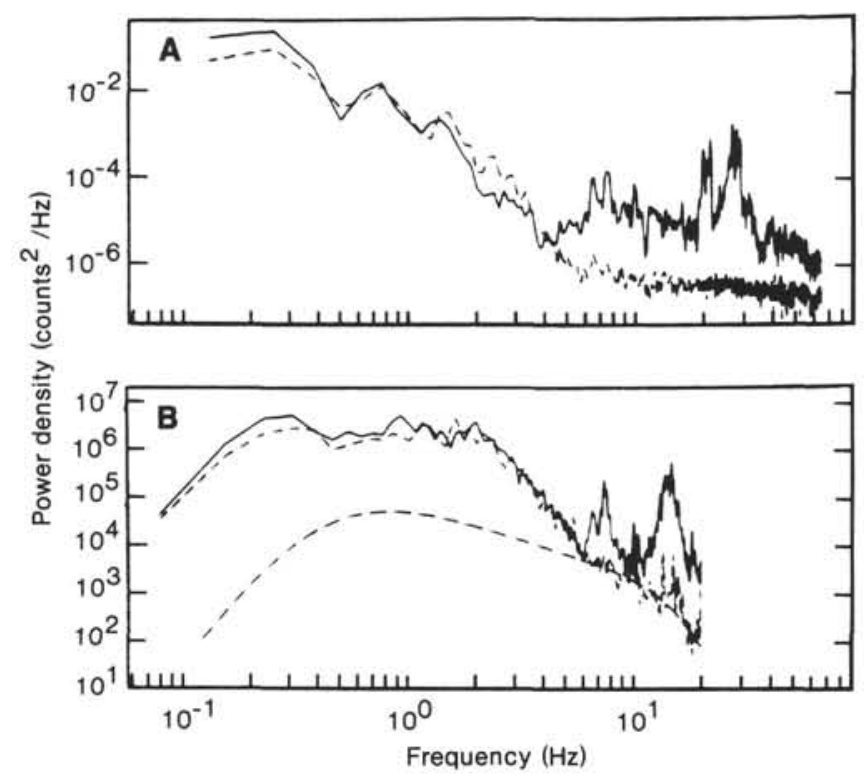

Figure 16. Illustration of ship noise in the (A) OBS and (B) MSS data. Solid spectra were observed when ships were nearby and operational, and the dashed spectra when ships were completely absent (OBS) or still nearby (MSS). MSS data are not available at any time when ships were completely absent.

mode has a phase velocity $C_{p}$ of $1.0-1.5 \mathrm{~km} / \mathrm{s}$, corresponding to a wavelength $\lambda=C_{p} / f$ on the order of $5 \mathrm{~km}$. The capsule separation, roughly $\lambda / 10$, is too large to account for the observed small cross-phases; this rules out the oblique arrival of the microseism energy from a distant source. It therefore appears that the microseism source location in this instance is either local or along a line that is approximately normal to a line defined by

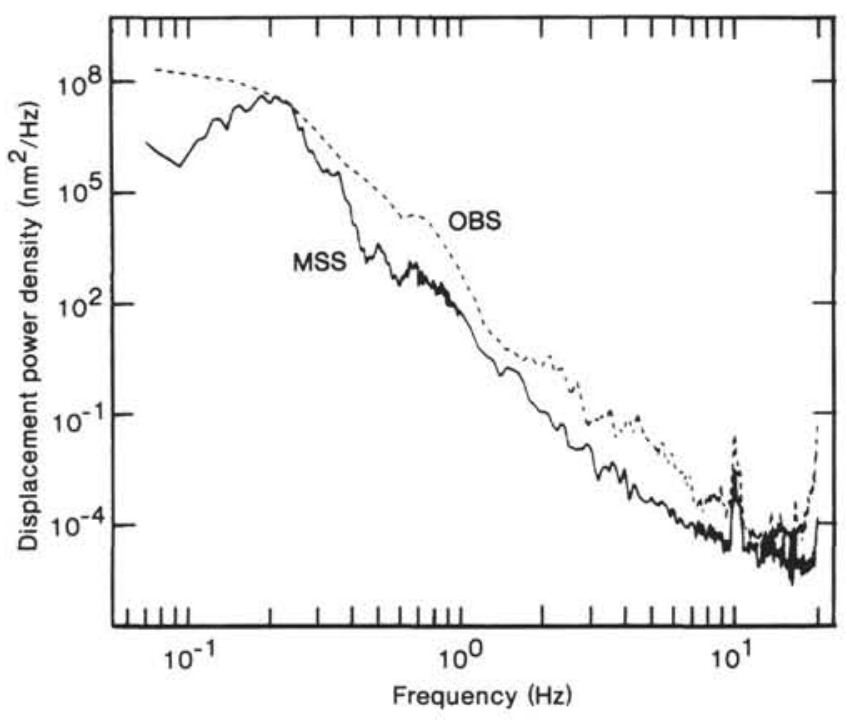

Figure 17. Simultaneous vertical-component displacement power densities at the ocean bottom (dashed line) and in the borehole (solid line).

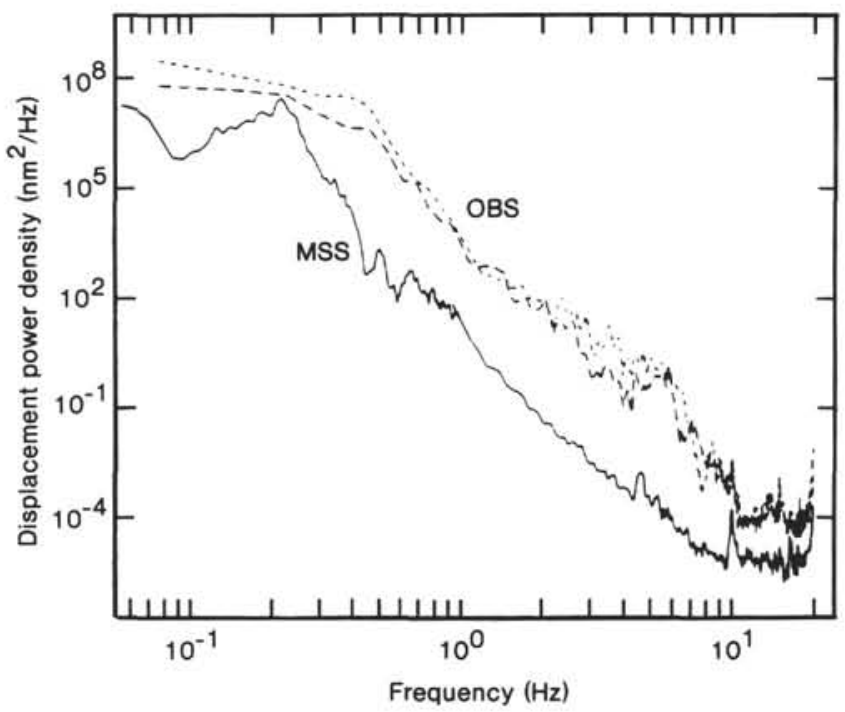

Figure 18. Simultaneous horizontal-component displacement power densities at the ocean bottom (dashed line) and in the borehole (solid line).

the OBSs. Coherences between OBSs Juan and Lynn, separated by $0.7 \mathrm{~km}$, exhibit similar coherences and crossphases near the microseism peak.

The vertical-component spectra of Figure 17 are compared in Figure 26 with extrema of similar measurements from Scripps Institution of Oceanography (SIO) OBSs. Above $\sim 1.5 \mathrm{~Hz}$, the Leg 91 measurements are comparable to the lower extreme and fall off at a similar rate. This is despite the fact that the observation sites and conditions were quite disparate. The extrema are not well defined at lower frequencies because of the short data sample lengths from which the spectra were obtained.

Figure 27 compares the Figure 17 spectra to unusually low noise observations on land. The Lajitas spec- 


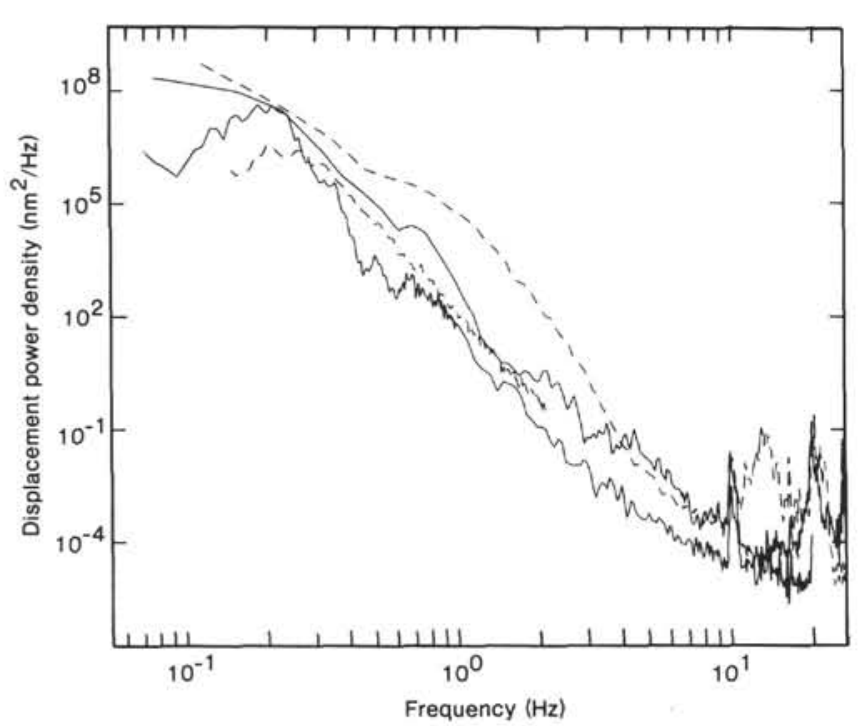

Figure 19. A comparison of vertical-component ocean-bottom and borehole noise levels observed during DSDP Leg 78B (dashed curves) and during the Ngendei Experiment, Leg 91 (solid curves).

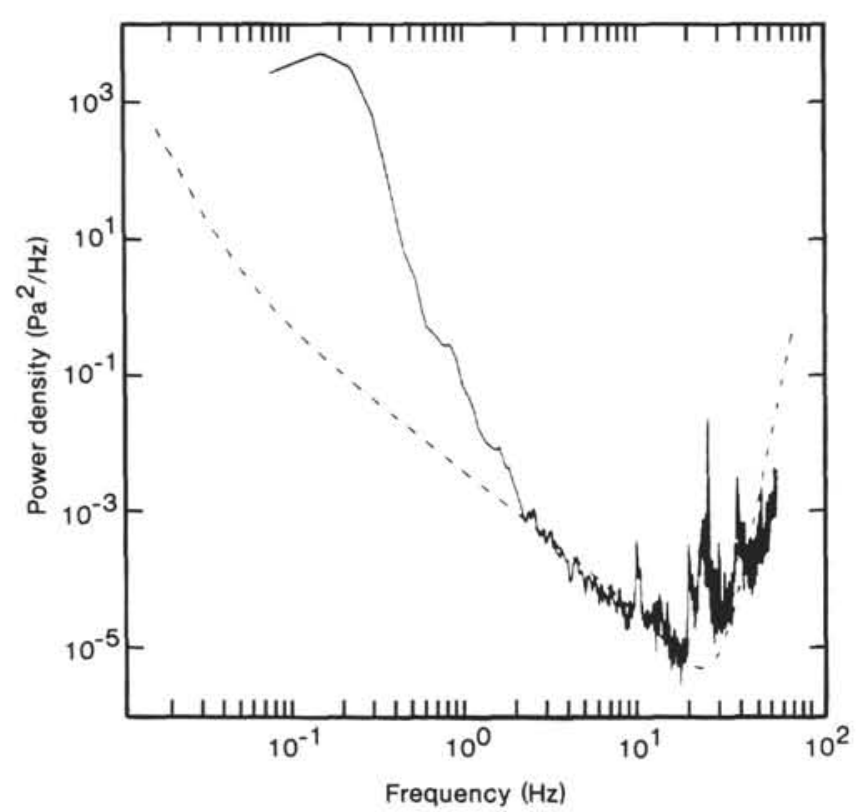

Figure 20. Ocean-bottom pressure measurements concurrent with the displacement spectra of Figure 17.

trum (Herrin, 1982) is representative of the quietest known site, which is near the Big Bend of the Rio Grande River. At frequencies less than $2 \mathrm{~Hz}$, Lajitas noise levels differ little from those measured at a quiet site in a mine shaft near Queen Creek, Arizona (Fix, 1972; Melton, 1976), so their composite delineates the lowest known noise levels at these frequencies. The MSS levels exceed this composite by $20-35 \mathrm{~dB}$ below $2 \mathrm{~Hz}$, but converge to within $10 \mathrm{~dB}$ at higher frequencies. The OBS levels similarly exceed the composite by $35-45 \mathrm{~dB}$ below $2 \mathrm{~Hz}$, and converge to within $30 \mathrm{~dB}$ above $2 \mathrm{~Hz}$. The $10 \mathrm{~Hz}$ peak in the Lajitas spectrum is not related to that in the Ngendei spectra, which is ship-generated.

\section{CONCLUSIONS}

Comparable noise levels were observed at the microseism peak on all components at both the ocean bottom and in the borehole. However, at higher frequencies (0.3-4.5 $\mathrm{Hz}$ ), the borehole noise levels were substantially lower than the ocean-bottom levels for both vertical and horizontal components. If microseism peak noise is a trapped wave phenomenon, then the observation that the noise levels were comparable in the OBS and MSS at the microseism peak suggests that the borehole sensor was not sufficiently deep in the basaltic basement to diminish noise levels over the entire band of frequencies.

The analysis has yielded several constraints on both source character and noise propagation. The microseism peak displayed high coherence and a cross-phase consistent with simultaneous arrival over a distance of at least $0.7 \mathrm{~km}$. This suggests a local source for noise in the microseism peak range. The rate of fall-off of the OBS and MSS spectra from the microseism peak and the variety of peaks in the fall-off indicate both regional and local sources for noise in this frequency range. The peaks are probably due both to source spectrum shape and to resonant forcing of seismic modes trapped near the seafloor-ocean-bottom interface. The observed vertical- and horizontal-component noise levels in the borehole and at the ocean bottom constrain the mode of noise propagation. In the MSS vertical component, noise was insignificantly $(4 \mathrm{~dB})$ higher than the noise levels measured in the horizontal components, whereas there was a 10-20 dB difference in the OBS horizontal and vertical component noise levels. Since changes with depth in horizontal amplitude and the ratio of horizontal to vertical amplitudes are different for different types of interface waves, detailed investigation of these differences would constrain the mode of noise propagation.

Spectral slopes of the pressure noise at frequencies less than approximately $2 \mathrm{~Hz}$ were not consistent in the instances considered here with those expected from equilibrium wind-wave generation. The flattening of the pressure spectrum seen at frequencies greater than $2 \mathrm{~Hz}$ is probably due to distant shipping noise.

The borehole noise levels observed during the Ngendei Experiment are comparable to average continental sites, and approach exceptionally quiet land levels only at frequencies above $10 \mathrm{~Hz}$. Deeper burial may have some effect on the noise levels, reducing levels in the microseism peak somewhat closer to levels in quiet land sites.

Modeling of the phase spectrum, relative amplitudes and coherences between different sites and components, and spectral shape should yield a better more sophisticated characterization of the noise and source fields. These phenomena will be the subject of further research using the Ngendei noise data.

\section{ACKNOWLEDGMENTS}

The authors thank Chip Cox for his useful review. This research was supported by DARPA contracts F49620-79-C-0019 and AFOSR84-0043.

\section{REFERENCES}

Adair, R. G., Orcutt, J. A., and Jordan, T. H., 1984. Analysis of ambient seismic noise recorded by downhole and ocean-bottom seis- 
mometers on Deep Sea Drilling Project Leg 78B. In Hyndman, R. D., Salisbury, M. H., et al., Init. Repts. DSDP, 78B: Washington (U.S. Govt. Printing Office), 767-781.

Bendat, J. S., and Piersol, G. G., 1971. Random Data: Analysis and Measurement Procedures: New York (John Wiley).

Bradner, H., 1962. Pressure variations accompanying a plane wave propagated along the ocean bottom. J. Geophys. Res., 67:36313633.

Bradner, H., and Dodds, J. G., 1964. Comparative seismic noise on the ocean bottom and on land. J. Geophys Res., 69:4339-4348.

Creager, K. C., and Dorman, L. M., 1982. Locations of instruments on the seafloor by joint adjustment of instrument and ship positions. J. Geophys. Res., 87:8379-8388.

Duennebier, F. K., and Blackinton, G., 1983. The ocean subbottom seismometer. In Geyer, R. (Ed.), Geophysical Exploration at Sea: Boca Raton (CRC Press), 317-332.

Fix, J. E., 1972. Ambient earth motion in the period range from 0.1 to 2560 sec. Bull. Seism. Soc. Am., 62:1753-1760.

Hasselmann, K., 1963. A statistical analysis of the generation of microseisms. Rev. Geophys., 1:177-210.

Herrin, E., 1982. The resolution of seismic instruments used in treaty verification research. Bull. Seism. Soc. Am., 72:S61-S67.

Hyndman, R. D., Salisbury, M. H., et al., 1984. Init. Repts. DSDP, 78B: Washington (U.S. Govt. Printing Office).

Jenkins, G. M., and Watts, D. G., 1968. Spectral Analysis and its Applications: San Francisco (Holden-Day).

Latham, G. V., Anderson, R. S., and Ewing, M., 1967. Pressure variations produced at the ocean bottom by hurricanes. J. Geophys. Res., 72:5693-5704.

Latham, G. V., and Nowroozi, A. A., 1968. Waves, weather, and ocean bottom microseisms. J. Geophys. Res., 73:3945-3956.

Latham, G. V., and Sutton, G. H., 1966. Seismic measurements on the ocean floor, 1. Bermuda area. J. Geophys. Res., 71:2545-2572.

Longuet-Higgins, M. S., 1950. A theory of the origin of microseisms. Phil. Trans. R. Soc. London, A, 243:1-35.

Melton, B. S., 1976. The sensitivity and dynamic range of inertial seismographs. Rev. Geophys. Space Phys., 14:93-116.

Moore, R. D., Dorman, L., Huang, C.-Y., and Berliner, D. L., 1981. An ocean bottom, microprocessor based seismometer. Mar. Geophys. Res., 4:451-477.

Nichols, R. H., 1981. Infrasonic ambient ocean noise measurements: Eleuthera. J. Acoust. Soc. Am., 69:974-981.
Otnes, R. K., and Enochson, L., 1982. Digital Time Series Analysis: New York (John Wiley).

Prentiss, D. D., and Ewing, J. I., 1963. The seismic motion of the deep ocean floor. Bull. Seism. Soc. Am., 53:765-781.

Schneider, W. A., and Backus, M. M., 1964. Ocean-bottom seismic measurements off the California coast. J. Geophys. Res., 69:11351143.

Schneider, W. A., Farrell, P. J., and Brannian, R. E., 1964. Collection and analysis of Pacific ocean-bottom seismic data. Geophysics, 29: 745-771.

Singleton, R. C., 1969. An algorithm for computing the mixed radix fast Fourier transform. IEEE Trans. Audio Electroacoust., AU-17: 93-103.

Spudich, P., and Orcutt, J., 1980. Petrology and porosity of an oceanic crustal site: Results from wave form modeling of seismic refraction data. J. Geophys. Res., 85:1409-1433.

Stephen, R. A., Johnson, S., and Lewis, B., 1983. The oblique seismic experiment on Deep Sea Drilling Project Leg 65. In Lewis, B. T. R., Robinson, P., et al., Init. Repts. DSDP, 65: Washington (U.S. Govt. Printing Office), 319-328.

Stephen, R. A., Louden, K. E., and Matthews, D. H., 1980. The oblique seismic experiment on Deep Sea Drilling Project Leg 52. In Donnelly, T., Francheteau, J., Bryan, W., Robinson, P., Flower, M., Salisbury, M., et al., Init. Repts. DSDP, 51, 52, 53, Pt. 1: Washington (U.S. Govt. Printing Office), 675-704.

Sutton, G. H., Duennebier, F. K., and Iwatake, B., 1981. Coupling of ocean bottom seismometers to soft bottom. Mar. Geophys. Res., 5:35-51.

Urick, R. J., 1974. Sea-bed motion as a source of the ambient noise background of the sea. J. Acoust. Soc. Am., 56:1010-1011. 1983. Principles of Underwater Sound (3rd ed.): New York (McGraw-Hill).

Webb, S. C., 1984. Observations of seafloor pressure and electric field fluctuations [Ph.D. dissert.]. University of California, San Diego.

Welch, P. D., 1967. The use of Fast Fourier Transform for the estimation of power spectra: A method based on time averaging over short, modified periodograms. IEEE Trans. Audio Electro-acoust., AU-15:70-73.

Date of Initial Receipt: 14 February 1985

Date of Acceptance: 28 January 1986 


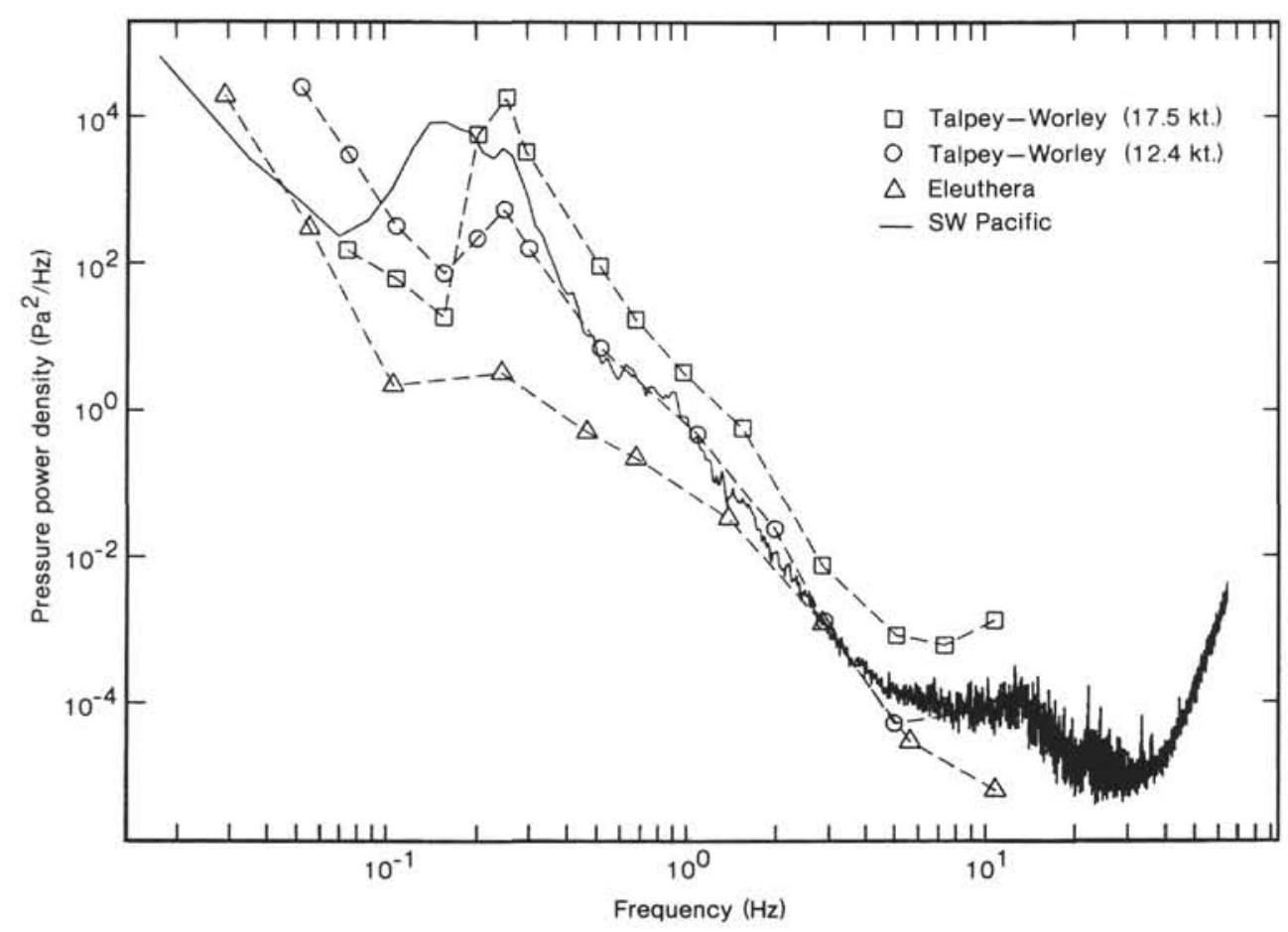

Figure 21. Ocean-bottom pressure measurements observed on OBS Suzy at $5.6 \mathrm{~km}$ water depth, during the period 12 February-22 March 1983, compared with high-resolution measurements reported by Nichols (1981). See text for explanation of key. Given for the Talpey-Worley spectra are the average wind speeds during data collection.

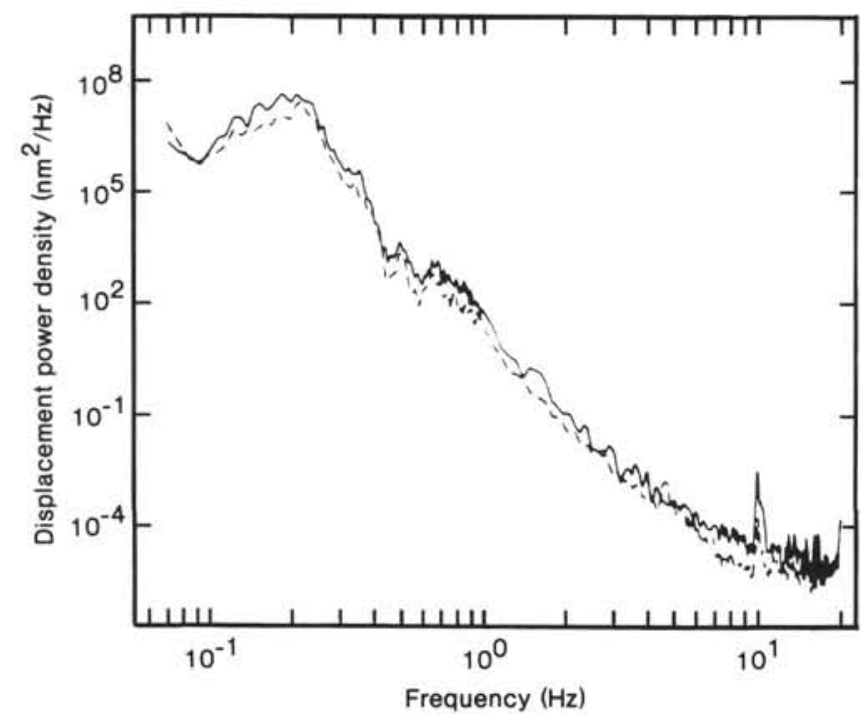

Figure 22. Simultaneous vertical (solid) and horizontal (dashed) power densities in the borehole.

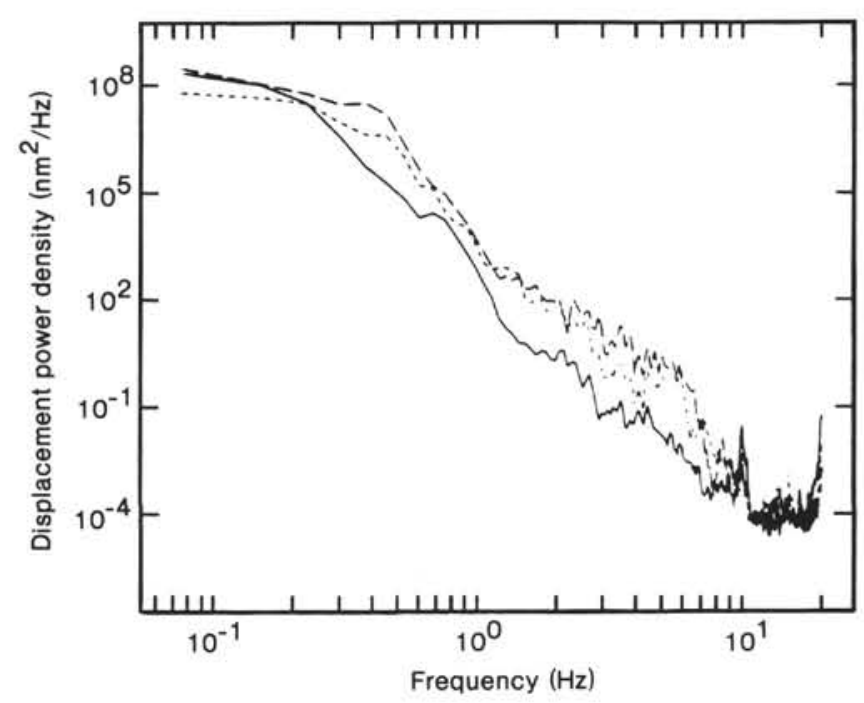

Figure 23. Simultaneous vertical (solid) and horizontal (dashed) power densities at the ocean bottom. 

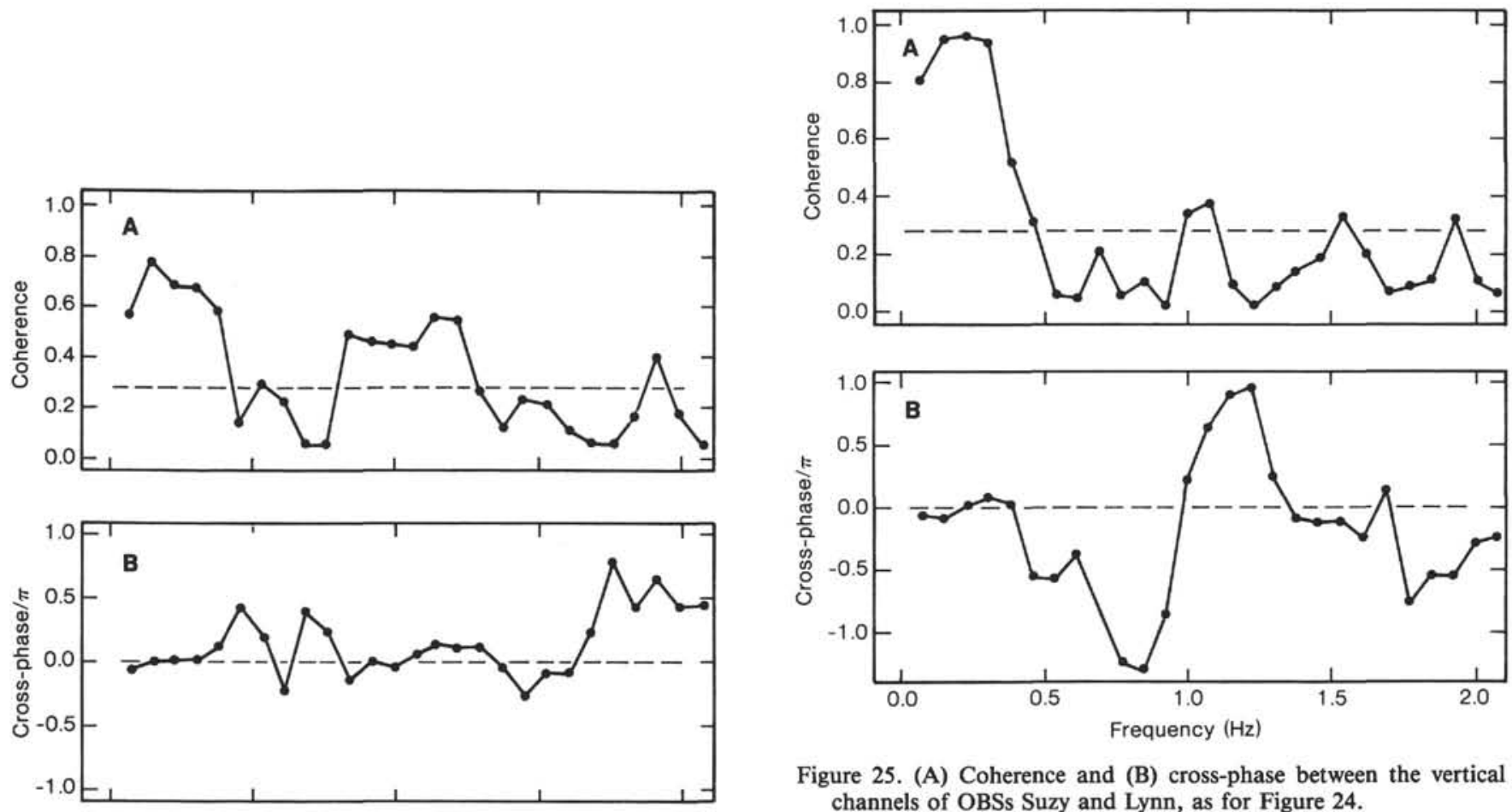

Figure 25. (A) Coherence and (B) cross-phase between the vertical channels of OBSs Suzy and Lynn, as for Figure 24.

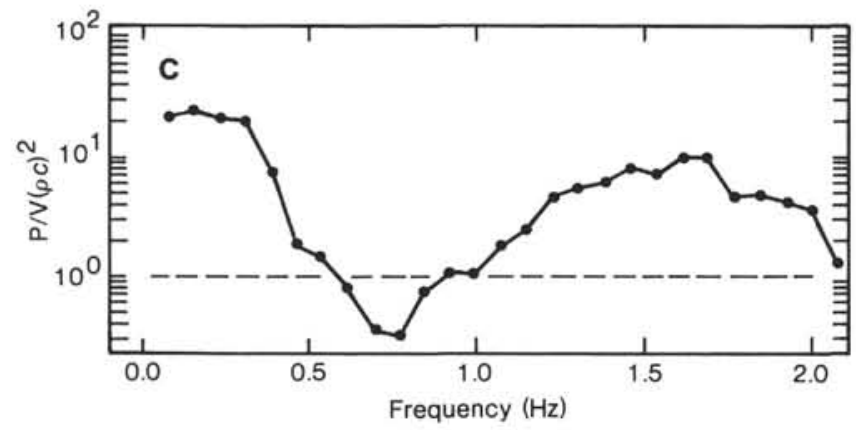

Figure 24. (A) Coherence and (B) cross-phase between OBS Suzy channels Z (vertical) and P (hydrophone). The cross-phase, plotted in multiples of $\pi$, has been corrected for instrument response phase. C. The ratio between OBS Suzy pressure and vertical ground-velocity power densities, normalized by the product of density and acoustic speed in the water.

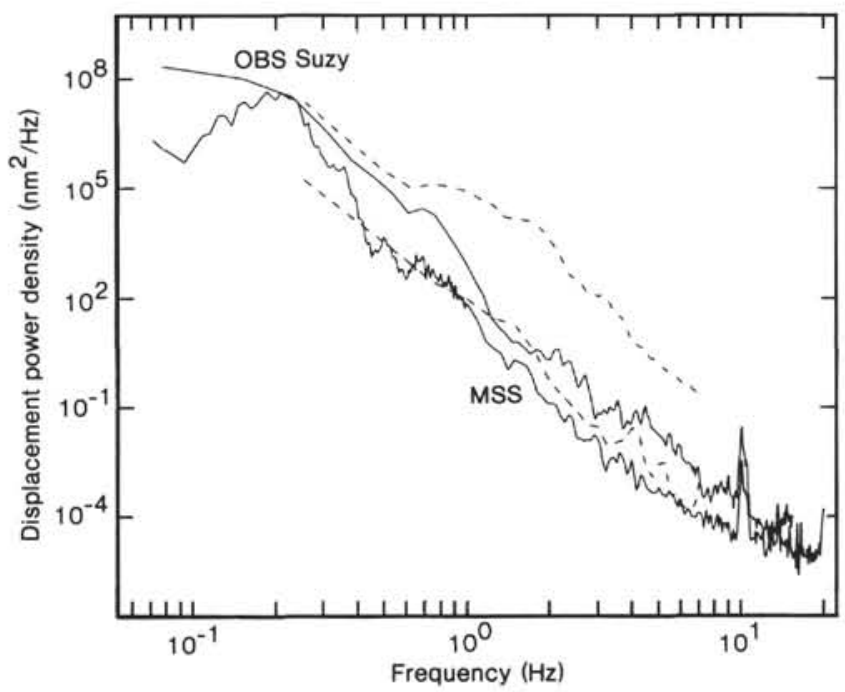

Figure 26. Comparison of vertical-component noise of Figure 17 with extrema (dashed lines) observed on Scripps Institution of Oceanography OBSs during their 12-yr. program. 


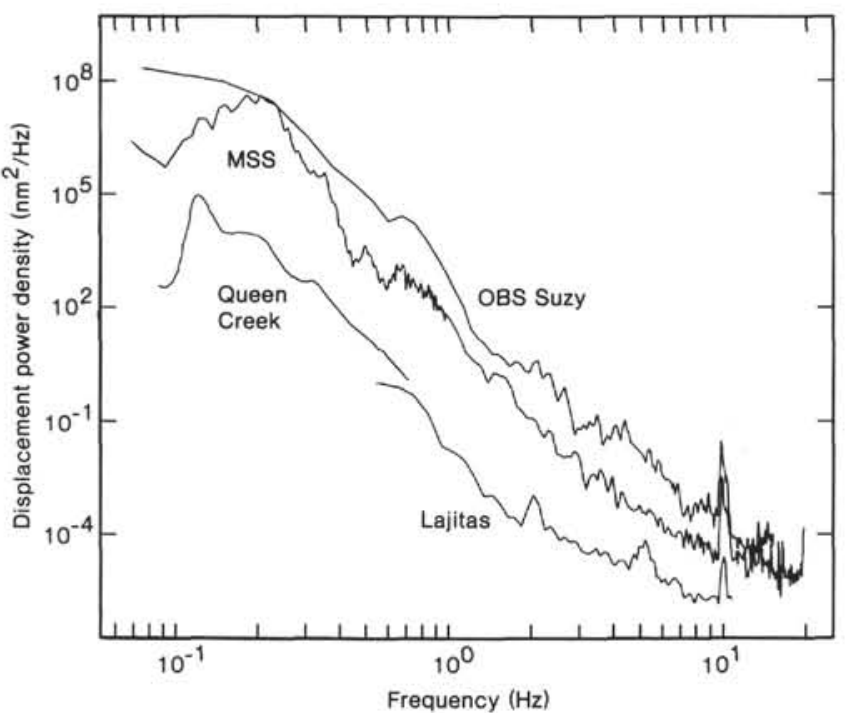

Figure 27. Comparison of vertical component noise observations from the Ngendei Experiment with extremely low level observations at land sites. The composite of the Queen Creek and Lajitas spectra may be taken as the lowest known microseism levels at these frequencies. 